\title{
FABRIC-REINFORCED CEMENTITIOUS MATRIX BEHAVIOR AT HIGH-TEMPERATURE: EXPERIMENTAL AND NUMERICAL RESULTS Jacopo Donnini ${ }^{1}$, Francisco De Caso y Basalo ${ }^{2}$, Valeria Corinaldesi ${ }^{3}$, Giovanni Lancioni ${ }^{4}$, Antonio Nanni ${ }^{5}$
}

${ }^{1}$ Università Politecnica delle Marche, Engineering Faculty, Ancona, Italy, j.donnini@univpm.it

${ }^{2}$ University of Miami, Dept. of Civil, Arch. \& Environ. Engineering, Miami, U.S.A., f.decasoybasalo@umiami.edu

${ }^{3}$ Università Politecnica delle Marche, Engineering Faculty, Ancona, Italy, v.corinaldesi@univpm.it

${ }^{4}$ Università Politecnica delle Marche, Engineering Faculty, Ancona, Italy, g.lancioni@univpm.it

${ }^{5}$ University of Miami, Dept. of Civil, Arch. \& Environ. Engineering, Miami, U.S.A., nanni@umiami.edu

\begin{abstract}
The use of externally applied composite systems to upgrade, strengthen or rehabilitate masonry or concrete structures is well established. However, structural strengthening with organic type composites, such as fiber-reinforced polymer (FRP) systems, may be impractical when the element is exposed to high-temperature service conditions, due to significant degradation of the organic resin. Instead, the use of an inorganic matrix, as in the case of fabric-reinforced cementitious matrix (FRCM) composites, may overcome this problem.

The purpose of this study is to evaluate the mechanical behavior under high-temperature conditions of FRCM systems. Different FRCM composites are evaluated and include carbon fabrics ranging from dry to highly-impregnated with an organic resin. The experimental spectrum is comprised of uniaxial tensile and double-shear bond tests performed under temperatures ranging from 20 to $120^{\circ} \mathrm{C}$ to determine the influence of temperature over the FRCM mechanical properties. Furthermore, SEM analysis was used to study the damage processes at the fiber-matrix interface post tensile testing. Experimental results show variations in the FRCM mechanical properties if tested at high temperature conditions (caused by the deterioration of the resin coating at the interface fiber-matrix) while residual performance after exposure to elevated temperatures remains unchanged. FRCM reinforced with dry fabrics has proven not to be affected by temperatures up to $120^{\circ} \mathrm{C}$.

A numerical model using a fracture variational approach, based on incremental energy minimization, was also developed to simulate the FRCM behavior in double shear tests under different temperatures exposition.
\end{abstract}

Keywords:

FRCM, Temperature, Organic Coating, Strengthening, Damage Mechanics, Variational Modelling. 


\section{Nomenclature}

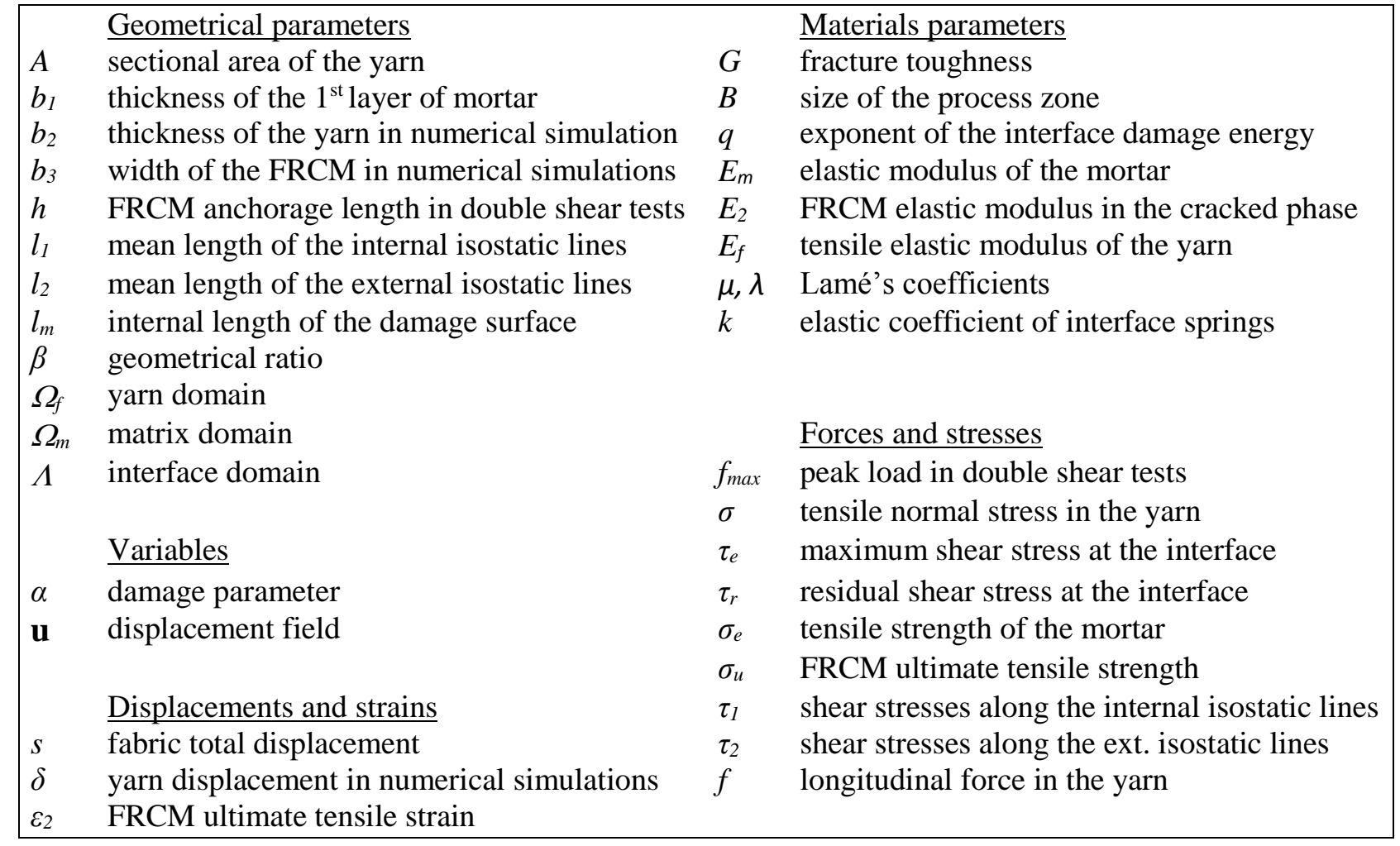

\section{Introduction}

The use of fiber-reinforced polymer (FRP) systems to reinforce masonry or concrete structures may be impractical when the element is exposed to high-temperature service conditions. FRP mechanical properties can be drastically reduced if the temperature exceeds the glass transition temperature $\left(\mathrm{T}_{\mathrm{g}}\right)$ of the organic resin used for fiber impregnation and bond to the substrate. Experimental studies showed a severe reduction of FRP tensile strength, stiffness and bond properties to the substrate when exposed to elevated temperatures due to a rapid deterioration of the FRP-substrate adhesion when the temperature exceeds the $\mathrm{T}_{\mathrm{g}}$ of the resin (typically around 60 to $80{ }^{\circ} \mathrm{C}$ ), resulting in delamination of the composite and loss of efficacy of the reinforcement [1-5].

Studies conducted by Bisby and co-workers [6] on the mechanical characterization of FRP materials at high temperature showed that half of the tensile strength of the FRP was lost when tested near the $\mathrm{T}_{\mathrm{g}}$ of the epoxy matrix. Lap-splice tests showed that the FRP-to-FRP bond strength was affected even more by temperature exposure near $\mathrm{T}_{\mathrm{g}}$ with $90 \%$ loss in lap-splice strength.

Al-Salloum and co-workers [7] suggested to not exceed the FRP $\mathrm{T}_{\mathrm{g}}$ in order to avoid serious consequences. In case temperature is allowed to reach up to $200{ }^{\circ} \mathrm{C}$ (thus greatly higher than $\mathrm{T}_{\mathrm{g}}$ ), the ultimate capacity of FRP-strengthened members should be kept at less than $25 \%$ of its corresponding value at room temperature.

For this reason, the use FRP composites in construction, where high temperature exposure is critical, may be limited and additional information is needed when selecting strengthening solutions. For example, the use of insulation to maintain the temperature on the FRP surface 
below $\mathrm{T}_{\mathrm{g}}$ is possible, although not always practicable $[8,9]$. Hence, alternative solutions need to be explored and evaluated.

FRCM systems use inorganic matrices, which are less susceptible to high temperature and may result cost effective compared to FRPs [10-15]. However, the bond between fibers and inorganic matrix is a critical issue in FRCM composites and is strongly influenced by the ability of the cementitious matrix to saturate dry fiber yarns; also affected is the bond between internal and external fibers within the yarns and between external fibers and matrix in case of dry fabrics and possibly between coating and matrix in case of coated fabrics. FRCM for structural strengthening applications is a relatively new material and durability is an important aspect to be considered. Factors affecting the durability of FRCM composite systems must consider the environmental performance of each of its components and their interfaces: the cementitious matrix, the fabric reinforcement, the fabric-matrix interface and the matrix-substrate interface are the different elements that need to be considered in relation to the service environments in which they are expected to perform [16]. FRCM is expected to overcome some of the issues that are typically found in FRP because of the better performance of the cementitious matrix to high temperatures. However, limited experimental and analytical studies have been conducted to evaluate the behavior of FRCM under high temperatures and the residual performances after exposure to elevated temperatures.

An experimental study on the effect of high temperature on the performance of carbon fiberreinforced polymer (CFRP) and FRCM confined concrete element was conducted by Trapko [17], using concrete cylinders reinforced with CFRP sheets and FRCM mesh and exposed to temperature ranging from 40 to $80{ }^{\circ} \mathrm{C}$. In the case of polymer jackets, $40{ }^{\circ} \mathrm{C}$ increase in temperature resulted in $20 \%$ decrease of the load-bearing capacity. The compressive strain of specimens tested in $80{ }^{\circ} \mathrm{C}$ was approximately half of the strain in specimens tested at 40 and 60 ${ }^{\circ} \mathrm{C}$. Load-bearing capacity decrease by $5-10 \%$ was observed for FRCM confined elements upon temperature increase from 40 to $80{ }^{\circ} \mathrm{C}$. Also, compressive strain decrease by approximately $11 \%$ was observed upon temperature increase from 40 to 60 and $80{ }^{\circ} \mathrm{C}$.

FRCM performances at high temperature exposure may change when fabrics are preimpregnated with polymeric resins. Experimental studies showed that the use of a polymer coating applied on carbon fabric may significantly increase the mechanical capacity of FRCM systems for both tensile and shear bond strengths when applied to masonry or concrete supports [18-20]. However, when the textile reinforcement is coated with a polymer, the bond performance between fibers and matrix is strongly affected by temperature [21].

Recent studies by Silva and co-workers [22] using FRCM reinforced with carbon fibers showed a polymer interlocking mechanism between filaments and matrix when heating the polymer coated fibers up to $150{ }^{\circ} \mathrm{C}$. This mechanism results in significant increases in the maximum pullout load. Krüger and Reinhardt [23] performed fire tests on four different I-shaped mortar beams reinforced with AR-glass and carbon textiles. The investigation was focused on the load bearing capacity of the composite during a fire test under constant load. In one of the cases a SBR (Butadien-Styrol) thermoplastic resin was used as coating in the fiber. The results showed to be very dependent on the fire behavior of the used fibers. Due to the softening of the SBR coating (around $90{ }^{\circ} \mathrm{C}$ ) the fiber-matrix interface rapidly deteriorated, resulting in fiber pullout and, subsequent, failure.

Michels and Motovalli [24] presented experimental results of the tensile strength decrease of coated carbon fiber yarns after high temperature exposure up to $1000^{\circ} \mathrm{C}$. The investigation was performed at room temperature on carbon fiber yarns after having been thermally subjected to 
constant temperature of $300,500,700$ and $1000{ }^{\circ} \mathrm{C}$ in a tube furnace for 30 minutes. It was observed that an exposure at $300^{\circ} \mathrm{C}$ for 30 minutes does not affect the mechanical properties of the analyzed reinforcement. However, a further increase in temperature results in significant damage to the material performance at $500{ }^{\circ} \mathrm{C}$ and no residual strength at $700{ }^{\circ} \mathrm{C}$. Tests on a reinforced concrete slab strip strengthened with a shotcrete layer including a composite mesh as tensile reinforcement was also investigated. Under a constant service load, the slab was exposed to fire with a temperature rise according to a European standard curve (ETK) for two hours. The slab could withstand the applied load under fire exposure, during which the composite mesh reached a temperature of about $440{ }^{\circ} \mathrm{C}$.

This study aims at understanding FRCM behavior under high-temperature conditions as provided by an environmental chamber. Specimen reinforcement included fabrics made of carbon fibers ranging from dry to highly impregnated with an organic resin. A series of uniaxial tensile tests and double shear bond tests were performed under temperatures up to $120{ }^{\circ} \mathrm{C}$ to understand the influence of temperature over the mechanical properties of the FRCM and, in particular, the variation of bond between fabric and matrix when organic resin pre-impregnation was applied to the fabric.

To better understand the experimental results, a variational damage model has been numerically implemented in a finite element code, and simulations have been performed, reproducing the FRCM different behaviors observed in double shear bond tests at different temperatures and different fibers impregnation. Modeling investigations have been conducted also in [25-27] to have an insight into experimental results. However, FRCM behavior based on variation damage models has never been reproduced.

The model proposed in this paper falls into the category of phase-field models, which, in the last decade, have been object of many researches, and have been applied to several problems of material science. The phase-field approach was first proposed in [28] for regularizing the Griffith's theory of brittle fracture, formulated as a minimum problem [29]. The sharp fracture of Griffith's theory is approximated by a smeared fracture, described by layers of finite thickness where the material damages and strains localize. An auxiliary scalar field $\alpha$ is introduced into the material internal energy functional, which plays the rule of a damage field assuming values $\alpha=0$ for sound material and $\alpha=1$ for totally damaged material, and an intrinsic length scale parameter controls the thickness of the damaged zone. When the length scale parameter goes to zero, the thickness of the damaged layer shrinks to zero, and sharp Griffith's fracture is recovered. Including both displacement and damage smooth fields, the model accounts for a straightforward implementation by standard finite elements. Since the formulation [28], many improved and enriched models have been proposed. Among the many, we mention [30], where the variational problem [28] has been reformulated in the more general framework of finite elasticity, [31], where the bulk energy has been decomposed into non damageable spheric and damageable deviatoric parts to reproduce shear fractures, and [32,33], where fracture under tensile and compression stress states has been differentiated.

Here, a phase-field model is developed for the double shear test, which is schematized by a twodimensional problem. Different energies are assigned to the cementitious matrix, to the fibers and to the matrix-fibers interface. While the fibers are supposed to be unbreakable, and thus they are purely elastic, the matrix is breakable. Its internal energy accounts for an elastic and a damage term. This latter is sum of a dissipative local contribution, a linear function of $\alpha$, and a non-local contribution depending on the gradient of $\alpha$, as in [34]. Materials with this energy 
exhibit a brittle-elastic mechanics. They deform elastically as long as a maximum stress value is attained, and, afterwards, they brutally damage and break.

A damageable elastic springs distribution is applied at the matrix-fibers interface. Its damage energy is sum of a local and a non-local gradient term, and the local contribution is a non-linear power function of $\alpha$. To our knowledge, the expression of the local damage energy is a novelty, never proposed in literature, and it allows of describing initial purely elastic regimes followed by stress-softening phases. Moreover, it allows of accounting for residual strength when large relative sliding displacements are attained, thus interpreting the frictional behavior observed in pullout tests. While the matrix and fibers material parameters are kept fixed, the parameters characterizing the interface vary with respect to temperature and type of fibers (dry or preimpregnated with organic resin). Thus, in the model, thermal and fibers impregnation affect only the interface parameters.

For a system characterized by these energies, the displacement and damage evolution, when certain loads are applied and increased, is determined by solving a constrained incremental minimization problem. Incremental minimization is a powerful mathematical tool to capture local minima in evolution problems, and it has been applied to problems of fracture [35], plasticity [36,37], and crystal plasticity [38,39]. Here it is solved numerically by implementing a Sequential Quadratic Programming algorithm.

The paper is organized as follows. In Section 2 the experimental investigation is explained. Section 3 describes the variational damage model used to reproduce the experimental results of double shear bond tests. In Section 4 the experimental results are reported and compared with numerical simulations in Section 5. Conclusions are drawn in Section 6.

\section{Experimental investigation}

Tensile tests were performed using a MTS 651 environmental chamber at temperatures of 20,80 and $120{ }^{\circ} \mathrm{C}$. A clevis grip system was used to anchor the specimens by means of metal plates epoxied to the ends of the FRCM coupons, in order to allow the slippage of the fabric within the matrix and to better investigate the influence of a coating when the system is exposed to high temperatures [AC434 - Acceptance criteria for masonry and concrete strengthening using fabricreinforced cementitious matrix (FRCM) composite systems]. In this case, the load is transferred only through the matrix to the fabric.

Double shear bond tests were also performed to evaluate the bond capacity of FRCM applied on clay brick substrate and the behavior at the fabric-mortar interface when exposed to the aforementioned temperatures.

\subsection{Materials}

In order to study the effects of enhancing the bond at the fabric-matrix interface with an organic coating on the FRCM fabric and the mechanical behavior of the system when exposed to different temperatures two kinds of carbon fabric are used: dry and highly impregnated with epoxy resin plus sand (HS), (Figure 1). 

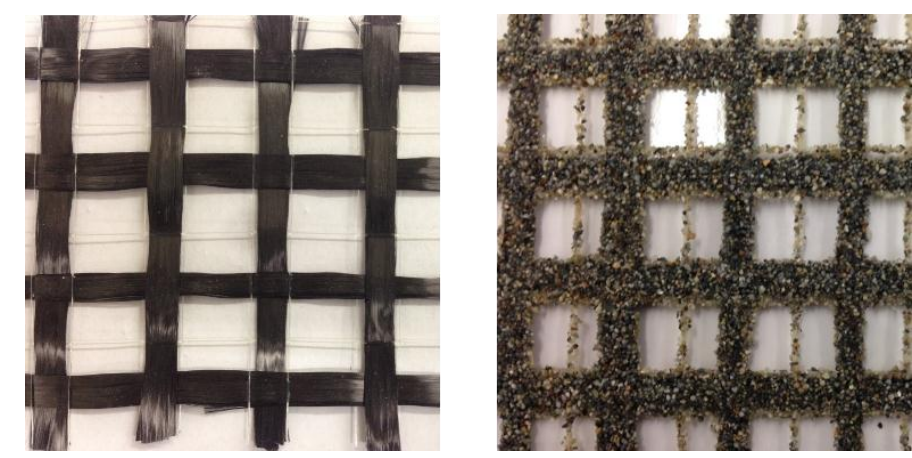

Figure 1. Dry and coated (HS) carbon fabrics

The enhancement of the bond is made by coating the fabric with a flexible epoxy and by applying a layer of quartz sand on the surface. Table 1 summarizes some of the geometrical and mechanical properties of the carbon fabric as obtained from the manufacturer. Values regarding mechanical properties of the carbon yarns (used in numerical analysis) were evaluated experimentally by means of tensile tests, according to EN ISO 10618/2005. The characteristics of the epoxy used as coating are reported in Table 2.

Table 1. Carbon Fabric characteristics

\begin{tabular}{|c|c|}
\hline \multicolumn{2}{|c|}{ Dry carbon fabric, bidirectional, balanced } \\
\hline $\begin{array}{l}\text { Resistant area (for each } \\
\text { direction) })^{1}\end{array}$ & $0.052 \mathrm{~mm}^{2} / \mathrm{mm}$ \\
\hline Fabric weight ${ }^{1}$ & $180 \mathrm{~g} / \mathrm{m}^{2}$ \\
\hline Fiber tensile strength ${ }^{1}$ & $4900 \mathrm{MPa}$ \\
\hline Fiber elastic modulus ${ }^{1}$ & $240 \mathrm{GPa}$ \\
\hline Fiber break elongation $^{1}$ & $2 \%$ \\
\hline Yarn tensile strength ${ }^{2}$ & $1850 \mathrm{MPa}$ \\
\hline Yarn elastic modulus, $E_{f}^{2}$ & $150 \mathrm{GPa}$ \\
\hline Yarn Poisson ratio, $v_{f}^{1}$ & 0.3 \\
\hline
\end{tabular}

Table 2. Coating characteristics obtain from manufacturer

Two component epoxy system

\begin{tabular}{lc}
\hline Tensile strength & $0.8 \mathrm{MPa}$ \\
Density & $1.12 \mathrm{~g} / \mathrm{m}$ \\
Max recommended operating & $50{ }^{\circ} \mathrm{C}$ \\
temperature & $70 \%$ \\
Strain at break & $58-68{ }^{\circ} \mathrm{C}$ \\
Exothermic peak & $6000 \mathrm{mPas}$ \\
Resin viscosity at $25^{\circ} \mathrm{C}$ & $1350 \mathrm{mPas}$ \\
\hline
\end{tabular}


The inorganic matrix used is a commercially available cementitious mortar, herein referred to as Mortar-45. The compressive and splitting tensile strengths were evaluated according to ASTM C109 and ASTM C496 [40,41] at 28 curing days, on $50 \mathrm{~mm}$ cubes and 50x100 mm cylinders, respectively. The Elastic modulus was evaluated according to ASTM C580 [42] and the average results of 5 repetitions are reported in Table 3.

Table 3. Mechanical properties of the mortar used as FRCM matrix

\begin{tabular}{lc}
\hline $\begin{array}{l}\text { Mortar 45 - Fiber-reinforced, structural } \\
\text { repair mortar }\end{array}$ \\
\hline Compressive strength & $50 \mathrm{MPa}$ \\
Elastic modulus, $E_{m}$ & $34.5 \mathrm{GPa}$ \\
Splitting tensile strength, $\sigma_{e}$ & $6.2 \mathrm{MPa}$ \\
Unit weight & $2275 \mathrm{~kg} / \mathrm{m}^{3}$ \\
Yarn Poisson ratio, $v_{m}$ & 0.2 \\
\hline
\end{tabular}

\subsection{Temperature profile}

A temperature profile along the length of the FRCM specimen was obtained, using type $\mathbf{J}$ thermocouples embedded in the mortar at four different locations (Figure 2). This allowed the possibility of measuring the temperature at the fabric-mortar interface when exposed to 80 and $120{ }^{\circ} \mathrm{C}$, while also understanding the effect of the metal tabs used to grip on the specimen.

Results depicted in Figure 3 shows a smooth increase of temperature of the FRCM specimen when no load is being applied, where after two hours the center of the specimen reached 88 and $90 \%$ of the peak applied temperature corresponding to the 80 and $120^{\circ} \mathrm{C}$ profile, respectively.
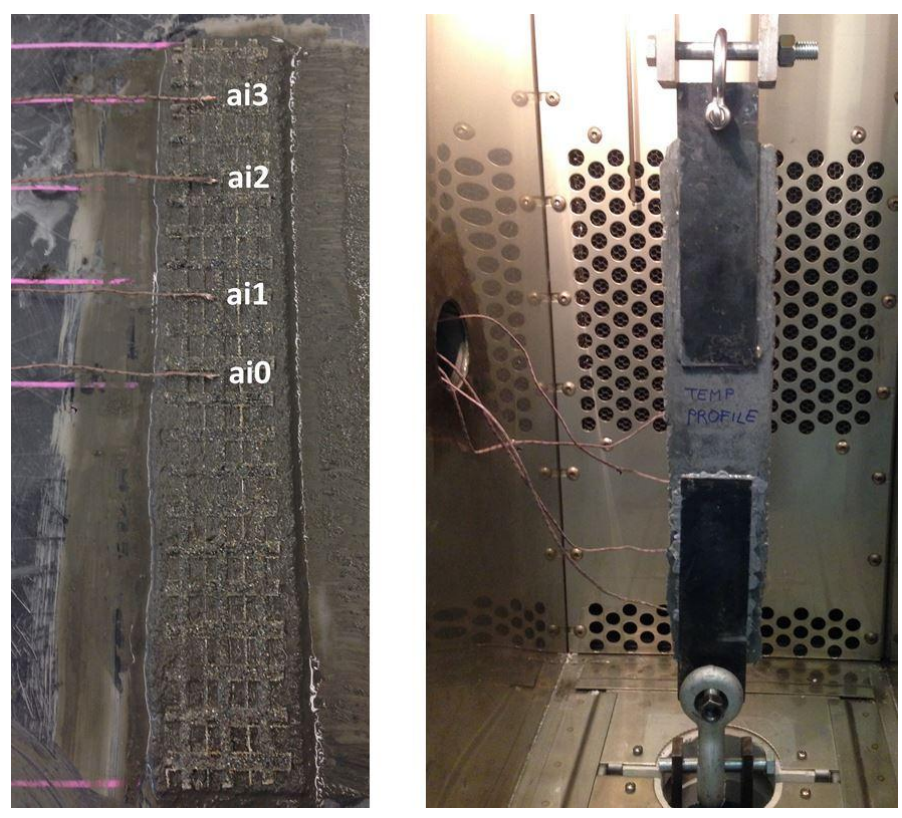

Figure 2. Application of thermocouples at the fabric-matrix interface 

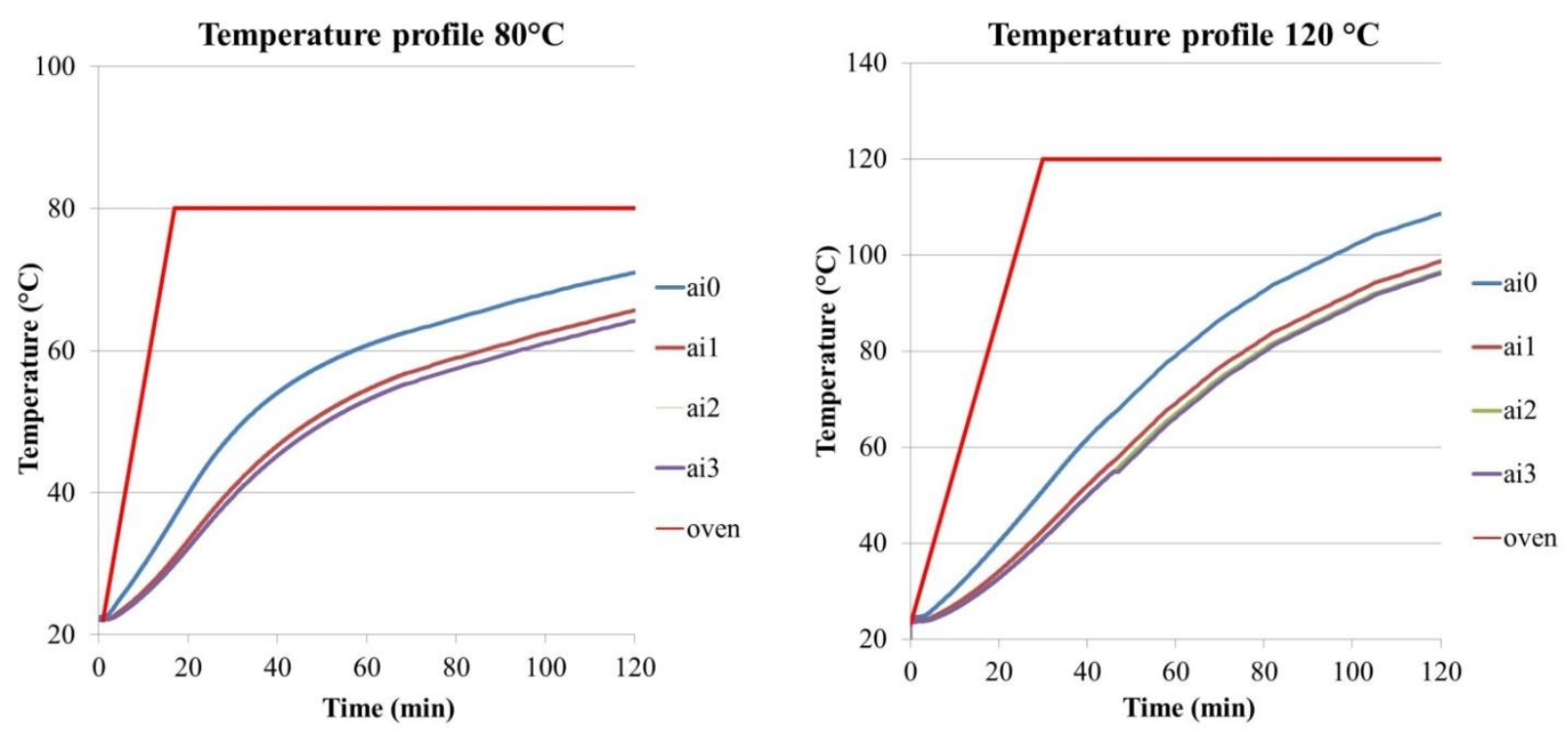

Figure 3. Heat development at the fabric-mortar interface of a FRCM coupon when exposed to 80 and $120^{\circ} \mathrm{C}$

Observation: the curve ai2 fits almost perfectly with the curve ai3, for this reason is not easily observable in the graph.

\subsection{Tensile and double shear bond test at high-temperature exposure}

FRCM behavior under high temperature exposure have been investigated by means of the two main tests to characterize this material: tensile test as described by AC434 Annex A and double shear bond test (RILEM TC250-CSM).

Tensile coupons 410x60x10mm were prepared and left to cure for 28 days at $20{ }^{\circ} \mathrm{C}$ and $70 \%$ relative humidity. Metal tabs were then adhered with epoxy to the ends of the specimens with an anchor length of $150 \mathrm{~mm}$, by using a special high-temperature epoxy able to withstand up to 150 ${ }^{\circ} \mathrm{C}$.

A total of 18 uniaxial tensile tests were conducted using a screw-driven universal test frame with a maximum capacity of $130 \mathrm{kN}$ and a MTS 651 Environmental Chamber. A clevis-type grip system was used and axial deformation was measured using a clip-on extensometer with a 100 $\mathrm{mm}$ gauge length, attached to the metal tabs surface. The load was applied under displacement control at $0.3 \mathrm{~mm} / \mathrm{min}$. Tensile tests were initiated after conditioning the specimens in the chamber for 100 minutes, so as to ensure the internal temperature at the center of the specimen failure zone was approximately $90 \%$ of the oven temperature, either 80 or $120{ }^{\circ} \mathrm{C}$.

A total of 12 double shear bond tests were performed on clay bricks substrates. Specimens were fabricated with dry and coated carbon bidirectional fabrics, using the same type of cementitious mortar (Mortar-45). The bond length was kept constant and equal to $100 \mathrm{~mm}$. The fabric was wrapped around a rigid steel cylinder and the specimens were tested at $20{ }^{\circ} \mathrm{C}$ and after being exposed to $120{ }^{\circ} \mathrm{C}$ for 100 minutes by means of an environmental chamber. The load was applied under displacement control at $0.5 \mathrm{~mm} / \mathrm{min}$. The double shear test set-up and the principal failure mode by slippage of the fabric within the mortar are shown in Figure 4. 
Furthermore, 3 double shear bond tests have been performed to evaluate the residual capacity of FRCM after being exposed to high temperature. Specimens were placed in oven at $120{ }^{\circ} \mathrm{C}$ for 60 minutes, cooled down and tested at $20^{\circ} \mathrm{C}$. A test matrix that summarizes all experimental tests is illustrated in Table 4.

Table 4. Test matrix

\begin{tabular}{|c|c|c|c|c|}
\hline Test & $\begin{array}{c}\text { Carbon } \\
\text { fabric }\end{array}$ & \# Tests & $\begin{array}{l}\text { Temperature of } \\
\text { testing }\left({ }^{\circ} \mathrm{C}\right)\end{array}$ & Description \\
\hline \multirow{2}{*}{$\begin{array}{c}\text { Tensile } \\
\text { Test }\end{array}$} & DRY & $3,3,3$ & $20,80,120$ & \multirow{4}{*}{$\begin{array}{l}\text { Specimens have been tested after being exposed } \\
\text { to the reference temperature for } 100 \text { minutes }\end{array}$} \\
\hline & HS & $3,3,3$ & $20,80,120$ & \\
\hline \multirow{3}{*}{$\begin{array}{c}\text { Double } \\
\text { shear } \\
\text { bond } \\
\text { test }\end{array}$} & DRY & 3,3 & 20,120 & \\
\hline & HS & 3,3 & 20,120 & \\
\hline & HS & 3 & 20 & $\begin{array}{l}\text { Specimens have been tested at room temperature } \\
\text { after being exposed at } 120^{\circ} \mathrm{C} \text { for } 60 \text { minutes }\end{array}$ \\
\hline
\end{tabular}
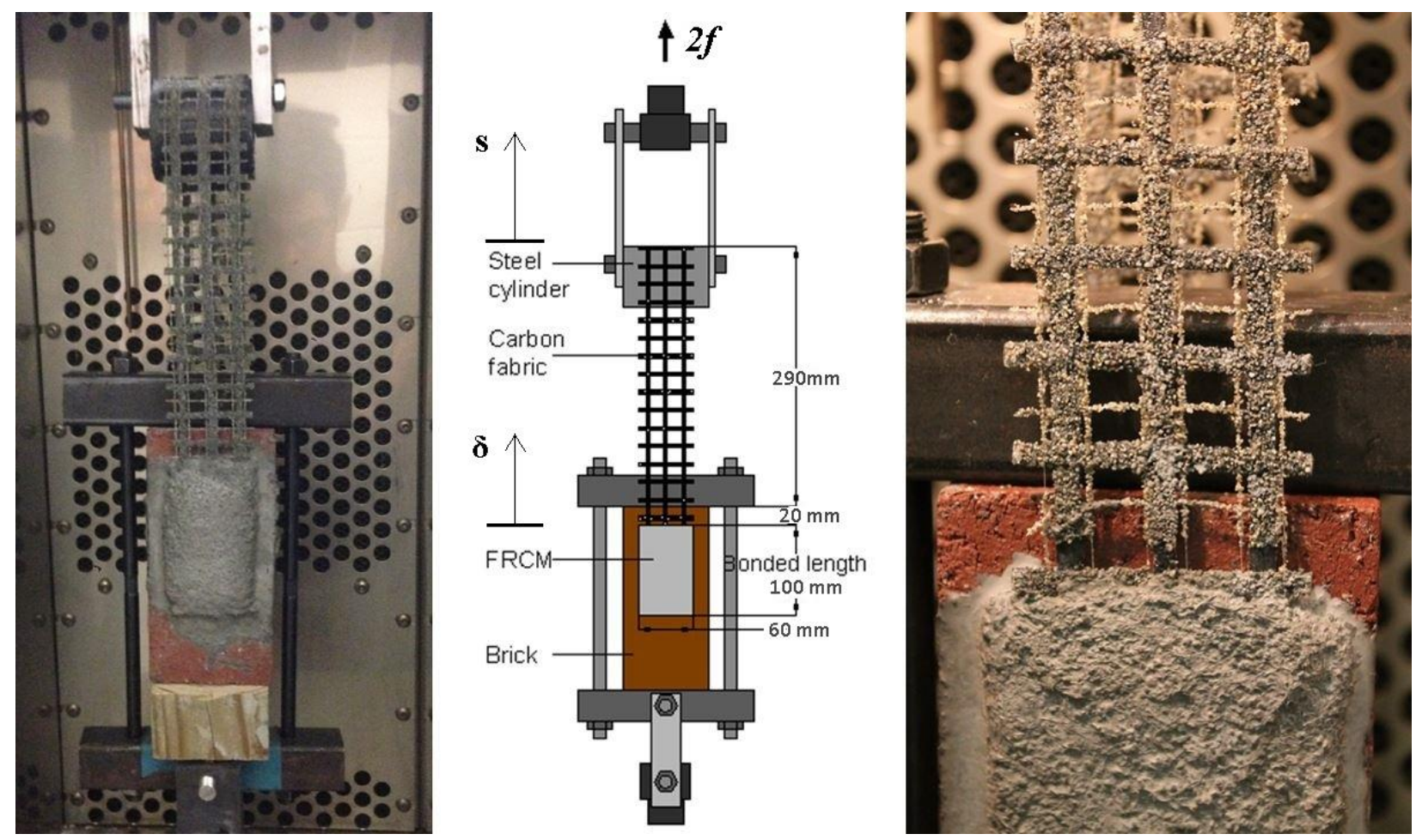

Figure 4. Double shear bond test set up and slippage failure mode

\section{Variational damage model for FRCM}

In this section, the variational damage model used to reproduce the experimental results of the double shear bond test is presented. In Sect. 3.1, the geometry of the experiment is simplified into a two-dimensional scheme, where the hypothesis of plane strain state is assumed. The energy assigned to the sample is discussed in Sect. 3.2, and, in Sect. 3.3, the damage evolution problem is formulated as an incremental energy minimization problem, and the numerical solving strategy is briefly recall. 


\subsection{Geometrical scheme for double shear bond test}

We consider a single yarn embedded in a cementitious matrix, as represented in Fig. 5a. The system is fixed to a rigid support (clay brick substrate) on one lateral side, and the yarn is subject to a constant displacement $\delta$. It generates a tensile normal stress $\sigma$ in the yarn and a shear stress $\tau$ at the interface with the matrix, which flows toward the clamped sample side. The isostatic lines of shear stress in a transverse cross-section are schematically drawn in Fig. 5b. The amounts of shear stress flowing from the internal and external yarn faces (the half-surfaces opposite to the clamped and traction-free matrix sides, respectively) are determined as follows. Let us consider the green and blue isostatic lines of Fig. 5b, which flow from points placed on the internal and external yarn face, respectively, and whose lengths $l_{1}$ and $l_{2}$ are approximately mean lengths among all the lines flowing from the internal and external faces. For a sample portion of infinitesimal thickness $d y$, we estimate the vertical shear stresses flowing through the surfaces projection of the green and blue isostatic lines (green and blue surfaces in Fig. 5c). A schematic plane representation of these surfaces is drawn in Fig. 5d. Given a longitudinal force $f$ (per unit thickness) in the yarn, the shear stresses $\tau_{1}$ and $\tau_{2}$ flowing through the green and blue regions of length $l_{1}$ and $l_{2}$, are

$$
\tau_{1}=\frac{\beta}{1+\beta} \frac{d f}{d y}, \quad \tau_{2}=\frac{1}{1+\beta} \frac{d f}{d y}, \quad \text { with } \beta=\frac{l_{2}}{l_{1}} .
$$

They are determined by solving the equilibrium equation $\tau_{1}+\tau_{2}=\frac{d f}{d y}$, and the kinematical compatibility condition $\frac{\tau_{1}}{G} l_{1}=\frac{\tau_{2}}{G} l_{2}$, with $G=\frac{E}{2(1+v)}$ the shear modulus. Since $l_{1}$ and $l_{2}$ are mean lengths, the ratios $\beta /(1+\beta)$ and $1 /(1+\beta)$ in (1) give estimates of the tensile force rates transmitted to the clamped surface through the internal and external faces of the yarn, respectively. Thus, supposing a constant distribution of $\sigma$ in the yarn cross-section, stresses in the red yarn portion of area $\beta A /(1+\beta)$ are transmitted through the internal part of the matrix, while the stresses in the rose portion of area $A /(1+\beta)$ are transmitted through the external and lateral parts of the matrix. In D'Antino and Carloni $[43,44]$, the authors tested some single-lap shear FRCM specimens with and without the external matrix layer in order to study the role of the different matrix layers in the stress-transfer mechanism. It was found that the external layer increases the bond strength of about $10 \%$. Accordingly, in the model we set $\beta=9$, so that $9 / 10$ of the tensile force is transmitted to the support through the internal cementitious layer, and $1 / 10$ through the external layer.

We restrict the study to the sample portion between the yarn and the clamped side of the sample, where the most severe stress state is attained. Accordingly, we limit to the cross-section part drawn in Fig. 5e, where only the yarn portion of area $\beta A /(1+\beta)$ is considered (red area). It is supposed to be rectangular. Sliders at the boundaries reproduce the confining effect of the excluded part of the sample, and the isostatic lines simplify in equispaced straight lines, parallel each other. For this simplified geometry, the strain state is plane, belonging to planes parallel to the $x-y$ plane. The geometry of the plane problem is plotted in Fig. $5 \mathrm{e}$, with $h=100 \mathrm{~mm}, b_{1}=5$ $\mathrm{mm}, b_{2}=0.23 \mathrm{~mm}$ (determined for $A=1.04 \mathrm{~mm}^{2}$ and $b_{3}=4 \mathrm{~mm}$ ). 


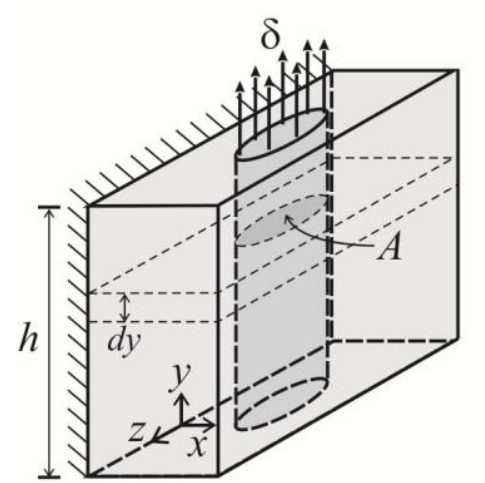

( a )

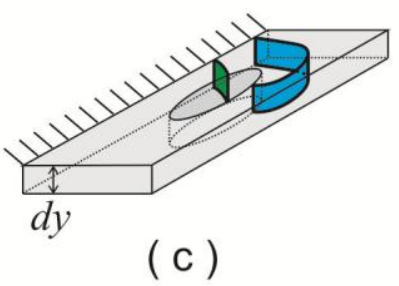

(c)

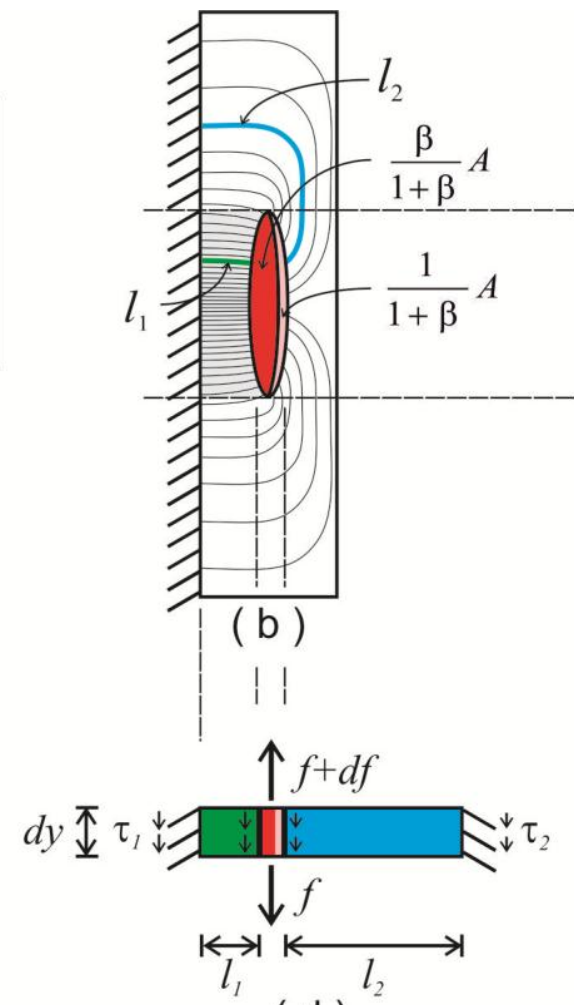

(d)

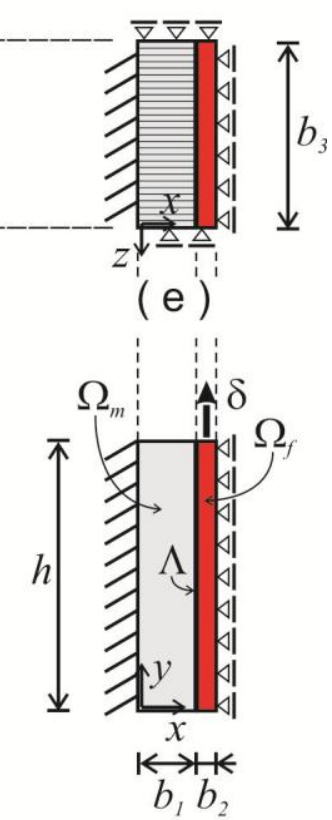

( $f$ )

Figure 5. Problem geometry. (a) Yarn-matrix geometry of the shear bond test. (b) Shear stress isostatic lines in a cross section. (c) Infinitesimal portion of the sample and representative isostatic surfaces (d) Shear stresses in the green (internal) and blue (external) isostatic lines. (e) Cross-section portion. $(f)$ Transversal section subject to plane strain state.

\subsection{Energies}

We refer to the geometrical scheme drawn in Fig. 5f, with $\Omega_{m}$ the matrix domain, $\Omega_{f}$ the yarn domain, and $\Lambda$ the matrix-yarn interface. The tensile displacement $\delta$ applied at the upper side of $\Omega_{f}$ monotonically increases from $\delta_{0}=0$ to a final positive value. Body loads are neglected, and the hypothesis of plane strain states is assumed. For a given Cartesian coordinate system $(O ; x, y)$, the displacement field is $\mathbf{u}(\mathbf{x})=[u(x, y), v(x, y)]^{T}$. We assign the following energies to $\Omega_{m}, \Omega_{f}$, and $\Lambda$.

Yarn energy. $\Omega_{f}$ is supposed to be made of an isotropic linearly elastic material. Its strain energy is

$$
\mathrm{E}_{f}(\mathbf{u})=\int_{\Omega_{f}}\left(\mu_{f}(\nabla \mathbf{u})^{2}+\frac{\lambda_{f}}{2}(\operatorname{div} \mathbf{u})^{2}\right) d \mathbf{x},
$$

where $\mu_{f}$ and $\lambda_{f}$ are the Lamé's coefficients.

Matrix energy. The cementitious matrix $\Omega_{\mathrm{m}}$ is supposed to be brittle, and its energy is

$$
\mathrm{E}_{h}(\mathbf{u}, \alpha)=\int_{\Omega_{f}}\left(W_{S}^{-}(\mathbf{u})+(1-\alpha)^{2}\left(W_{S}^{+}(\mathbf{u})+W_{D}(\mathbf{u})\right)\right) d \mathbf{x}+\int_{\Omega_{f}} d\left(\alpha+\frac{l_{m}^{2}}{2}(\nabla \alpha)^{2}\right) d \mathbf{x} .
$$


It depends on the displacement $\mathbf{u}$ and on the additional scalar field $\alpha(x): \Omega_{f} \rightarrow[0,1]$, which plays the role of a damage parameter. When $\alpha=0$, the material is intact, and, when $\alpha=1$ the material is completely fractured. The first integral in (3) represents the elastic strain energy. $W_{S}^{+}$ and $W_{S}^{-}$are the spherical parts of the energy, evaluated in points where volume expansion ( $\operatorname{div} \mathbf{u}>0$ ) and contraction ( $\operatorname{div} \mathbf{u}<0$ ), respectively, are attained, and $W_{D}$ is the deviatoric part of the energy, whose expressions are

$$
W_{S}^{ \pm}(\mathbf{u})=\left(\frac{\mu_{m}}{3}+\frac{\lambda_{m}}{2}\right)\left(\operatorname{div}^{ \pm} \mathbf{u}\right)^{2}, \quad W_{D}(\mathbf{u})=\mu_{m}(\nabla \mathbf{u})^{2}-\frac{\mu_{m}}{3}(\operatorname{div} \mathbf{u})^{2},
$$

with $d i v^{+} \mathbf{u}=\max \left(d i v^{+} \mathbf{u}, 0\right), \quad \operatorname{div}^{-} \mathbf{u}=\max \left(-\operatorname{div}^{-} \mathbf{u}, 0\right)$.

The second integral in (3) represents the damage energy, and it is sum of a local linear term and a quadratic non-local gradient term. Energies of the form (3) have been proposed in [32,33] for materials exhibiting different damage evolutions in the case of expansion and compression. When (3) is minimized, a competition is engaged between the first integral term, the elastic bulk strain energy, and the second integral term, the damage energy. The strain energy is minimized for fixed $\mathbf{u}$ by $\alpha=1$, while the damage energy is minimized by $\alpha=0$. However, the transition from $\alpha=0$ to $\alpha=1$ is associated with a non-null value of $\nabla \alpha$, indeed penalized by the second integrand of the damage energy, which represents an interface energetic term. Since $(1-\alpha)^{2}$ multiplies $\left(W_{S}^{+}+W_{D}\right)$ in the first integral, only the strain energy associated to expansion and shear enters into the competition with the damage energy. Thus, in the body regions where the volume change is negative, only the deviatoric part of the strain energy can be released by the creation of damage, and thus shear mode failures are energetically convenient (mode II failure). On the contrary, in the regions with positive volume change, the whole elastic energy may redeem the increments of the damage energy, and, as a result, mixed cleavage and shear failures evolve.

In $[34,45]$, the minimum problem associated to the functional (3) has been solved in the onedimensional setting of a tensile test, and the following simple formulas have been deduced

$$
d=\frac{\sigma_{e}^{2}}{E}, \quad l_{m}=\frac{B}{2 \sqrt{2}}, \quad G=\frac{4 \sqrt{2}}{3} d l_{m},
$$

which relate the constitutive parameters $d$ and $l_{m}$, characterizing the damage energy in (3), to easily measurable experimental data, obtained from tensile tests, i.e., the normal stress $\sigma_{e}$ attained at the end of the elastic phase, the fracture toughness $G$, the Young's modulus $E$, and the size $B$ of the so called process zone, i.e., that zone where damage develops and coalesces in a fracture surface. Formula $(5)_{2}$ clearly show that $l_{m}$ is an internal length of the material related to the width $B$ of the damage bands. In the simulations we determine $d$ and $l_{m}$ from (5) $)_{1,2}$, and (5) 3 gives an estimate of the fracture toughness.

In (2) and (4), Lamé's coefficients $\mu$ and $\lambda$ are related to the Young's modulus $E$ and Poisson's ratio $v$ by the formulas $\mu=\frac{E}{2(1+v)}, \lambda=\frac{E v}{(1+v)(1-2 v)}$.

Interface energy. A distribution of damageable elastic springs are assumed at the matrix-yarn interface $\Lambda$, whose energy is

$$
\mathrm{E}_{s}(\boldsymbol{\delta}, \alpha)=\int_{0}^{h}(1-\alpha)^{2} \frac{1}{2} \mathbf{K} \boldsymbol{\delta} \cdot \boldsymbol{\delta} d y+\int_{0}^{h} a\left(\frac{1}{q}\left((1-\alpha)^{-q}-1\right)+\frac{1}{2} l_{s}^{2}(\nabla \alpha)^{2}\right) d y .
$$


It depends on the displacement jump at the interface $\boldsymbol{\delta}(y)=\left[\delta_{x}(y), \delta_{y}(y)\right]^{T}=\left[u_{f}(b, y)-u_{m}(b, y), v_{f}(b, y)-v_{m}(b, y)\right]^{T}$, and on the interface damage $\alpha(y)$, with $y \in(0, h)$. As in (3), the first integral represents the elastic energy and the second integral accounts for the damage energy. The elastic coefficients $k_{x}$ and $k_{y}$ of the springs in the normal and tangential directions to the interface are collected in the elastic tensor $\mathbf{K}=\left[\begin{array}{cc}k_{x} & 0 \\ 0 & k_{y}\end{array}\right]$.

The damage energy is sum of two contributions, a power function of $\alpha$, and a non-local quadratic function depending on $\nabla \alpha$. To characterize the coefficients $a$ and $q$ in the damage energy, we solve the problem of an infinitesimal interface of length $d y$, subject to a shear stress $\tau$. If we suppose that $\delta_{x}=0$, the elementary interface energy is

$$
d \mathrm{E}_{s}\left(\delta_{y}, \alpha\right)=\left((1-\alpha)^{2} \frac{1}{2} k_{y} \delta_{y}^{2}+\frac{a}{q}\left((1-\alpha)^{-q}-1\right)-\tau \delta_{y}\right) d y,
$$

where the last term is the external energy due to the imposed shear load $\tau$. To determine an equilibrium configuration we require the energy first variation to be non-negative, $\delta d \mathrm{E}_{j}\left(\delta_{y}, \alpha ; \lambda, \beta\right) \geq 0$, for any admissible perturbations $(\lambda, \beta)$ such that $\beta \geq 0$. Following a standard variational procedure, we obtain the equilibrium relations

$$
\tau=(1-\alpha)^{2} k_{y} \delta_{y}, \quad-(1-\alpha) k_{y} \delta_{y}^{2}+a(1-\alpha)^{-(q+1)} \geq 0 .
$$

The first equation is the linear load-displacement relation due to the springs. The second relation is a damage criterion analogous to the criterion discussed in [34,45] for the uniaxial traction problem. The damage can evolve, when $(8)_{2}$ is satisfied as an equality, and it cannot, if $(8)_{2}$ is a strict inequality. In a process of increasing $\tau$, starting from an unstressed undamaged initial configuration $\tau=\delta_{y}=\alpha=0,(8)_{2}$ is strictly satisfied for $\alpha=0$ and $\delta_{y}<\sqrt{a / k_{y}}$, or, equivalently, $\tau<\sqrt{a k_{y}}$. Thus, for $0<\tau \leq \sqrt{a k_{y}}$, the evolution is purely elastic. The elastic undamaged phase ends when $\tau=\tau_{e}=\sqrt{a k_{y}}$ (and $\delta_{y}=\delta_{e}=\sqrt{a / k_{y}}$ ), from which we obtain

$$
a=\tau_{e}^{2} / k_{y} \text {. }
$$

This relation is used to calibrate the constitutive parameter $a$, since the right-hand side quantities are easily measurable from experiments. In the subsequent damage phase $\tau>\tau_{e}, \alpha$ grows, and $(8)_{2}$ is satisfied as an equality. We say that the evolution is stress-hardening (-softening) if $d \tau / d \alpha>0(<0)$, that is, if the stress increases (decreases) for $\alpha$ growing. From (8), the evolution is stress-hardening if $q>2$ and stress softening if $-2<q<2$. In Fig. 6 , dimensionless $\delta-\tau$ curves are plotted for different values of $q$. If we solve (8) with respect to $\alpha$ and $q$, for given values of $\delta_{y}=\delta_{r}$ and $\tau=\tau_{r}$, we obtain the expression

$$
q=-2\left(\frac{\log \left(k_{y} \delta_{r}^{2}\right)-\log a}{\log \tau_{r}-\log \left(k_{y} \delta_{r}\right)}+1\right)
$$

where log stands for the natural logarithm. Suppose that a pair $\left(\delta_{r}, \tau_{r}\right)$ is know from experiments. For instance, $\tau_{r}$ is the residual shear stress mainly due to friction attained at a large relative 
shear displacement $\delta_{r}$ (see the pair $\left(\delta_{r}, \tau_{r}\right)$ in the curve $q=-1$ of Fig. 6 ). Then (10) is used to calibrate the parameter $q$.

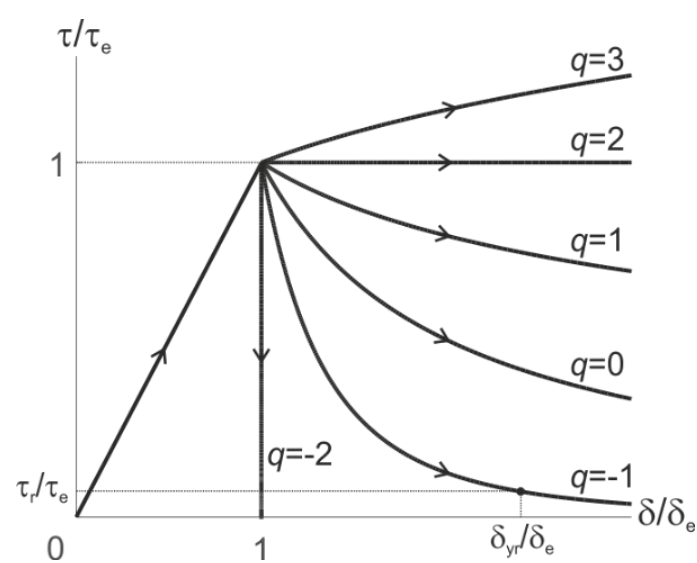

Figure 6. Response curves for different values of $q$.

The internal length $l_{s}$ in (6) is related to the length of the detachment front $D$, where $\alpha$ grows from 0 to 1 , by the relation $[34,45]$

$$
l_{s}=\frac{D}{\text { const }}, \quad \text { with const }=\int_{0}^{1} \sqrt{\frac{q}{(1-\alpha)^{-q}-1}} d \alpha .
$$

If we assume $q=-2$ of a brittle interface, we get const $=\pi \sqrt{2} / 2$, and thus $l_{s} \approx 0.45 D$.

Total Energy. The internal energy of the system is sum of the energies (2), (3) and (6)

$$
\mathrm{E}(\mathbf{u}, \alpha)=\mathrm{E}_{f}(\mathbf{u})+\mathrm{E}_{m}(\mathbf{u}, \alpha)+\mathrm{E}_{s}(\boldsymbol{\delta}(\mathbf{u}), \alpha) .
$$

Since volume and surface forces are null, it coincides with the total energy of the system.

\subsection{Incremental energy minimization}

The evolution of $\mathbf{u}$ and $\alpha$, for increasing $\delta$, is determined by means of incremental energy minimization. We introduce an evolution "time"-like parameter $t$, and suppose that $\delta$, $\mathbf{u}$ and $\alpha$ depend on $t$. In particular, $\delta$ is a monotonic increasing function of $t$. A subscript is used to indicate dependence on $t$, and a dot indicates derivative with respect to $t$, i.e, given a function $v=v_{t}(\mathbf{x}), \dot{v}=d v / d t$. Time is discretized into intervals of length $\tau$, and within each time step $t \rightarrow t+\tau$, we suppose that $\mathbf{u}$ and $\alpha$ are linear functions of $\tau$

$$
\mathbf{u}_{\mathrm{t}+\tau}=\mathbf{u}_{\mathrm{t}}+\tau \dot{\mathbf{u}}_{\mathrm{t}}, \quad \alpha_{\mathrm{t}+\tau}=\alpha_{\mathrm{t}}+\tau \dot{\alpha}_{\mathrm{t}},
$$

and that the energy (12) is approximated by the second-order development

$$
\mathrm{E}\left(\mathbf{u}_{\mathrm{t}+\tau}, \alpha_{\mathrm{t}+\tau}\right)=\mathrm{E}\left(\mathbf{u}_{\mathrm{t}}, \alpha_{\mathrm{t}}\right)+\tau \dot{\mathrm{E}}\left(\mathbf{u}_{\mathrm{t}}, \alpha_{\mathrm{t}} ; \dot{\mathbf{u}}_{\mathrm{t}}, \dot{\alpha}_{\mathrm{t}}\right)+\frac{1}{2} \tau^{2} \ddot{\mathrm{E}}\left(\mathbf{u}_{\mathrm{t}}, \alpha_{\mathrm{t}} ; \dot{\mathbf{u}}_{\mathrm{t}}, \dot{\alpha}_{\mathrm{t}}\right) .
$$

This latter rewrites in the form

$$
\mathrm{E}\left(\mathbf{u}_{\mathrm{t}+\tau}, \alpha_{\mathrm{t}+\tau}\right)=\mathrm{E}\left(\mathbf{u}_{\mathrm{t}}, \alpha_{\mathrm{t}}\right)+\tau \mathrm{F}\left(\dot{\mathbf{u}}_{\mathrm{t}}, \dot{\alpha}_{\mathrm{t}}\right) \text {, }
$$

with $\mathrm{F}\left(\dot{\mathbf{u}}_{\mathrm{t}}, \dot{\alpha}_{\mathrm{t}}\right)$ a quadratic functional of $\left(\dot{\mathbf{u}}_{\mathrm{t}}, \dot{\alpha}_{\mathrm{t}}\right)$. If $\left(\mathbf{u}_{\mathrm{t}}, \alpha_{\mathrm{t}}\right)$ at the instant $t$ is known, the solution (13) at $t+\tau$ is obtained by finding the pair $\left(\dot{\mathbf{u}}_{\mathrm{t}}, \dot{\alpha}_{\mathrm{t}}\right)$, which solves the constrained quadratic programming problem

$$
\left(\dot{\mathbf{u}}_{\mathrm{t}}, \dot{\alpha}_{\mathrm{t}}\right)=\arg \min \left\{\mathrm{F}\left(\dot{\mathbf{u}}_{\mathrm{t}}, \dot{\alpha}_{\mathrm{t}}\right), \dot{\alpha}_{\mathrm{t}} \geq 0,+ \text { boundary conditions }\right\} .
$$


A numerical code has been developed to solve the above problem. Discretized by linear triangular finite elements, the solution of (16) has been determined at each time step by means of an alternate iterative minimization procedure that consists in iterating the double minimization of $\mathrm{F}$, first with respect to $\dot{\mathbf{u}}_{\mathrm{t}}$, keeping $\dot{\alpha}_{\mathrm{t}}$ fixed, and then with respect to $\dot{\alpha}_{\mathrm{t}}$, for fixed $\dot{\mathbf{u}}_{\mathrm{t}}$. Iterations are stopped when the $L_{\infty}$-norm difference of two consequent solutions is smaller than a certain tolerance. Convergence and computational performances of this numerical scheme are thoroughly discussed in [46].

\section{Experimental results}

\subsection{Tensile test results}

FRCM specimens with coated carbon fabrics were significantly affected by external thermal exposure. Table 5 shows the average results based on three test repetitions. Even if the number of specimens tested was limited from a statistical point of view, and results should be confirmed by a larger experimental programme, the emerging line seems quite clear and it allows the considerations reported below. The decrease in mechanical properties of the FRCM system with coated fabrics when exposed to high temperatures is significant compared to those at room temperature when the ultimate tensile strength $\left(\sigma_{\mathrm{u}}\right)$ at 80 and $120{ }^{\circ} \mathrm{C}$ was found to be $70 \%$ lower compared to that at $20^{\circ} \mathrm{C}$ for the coated fabric, while the reduction of the ultimate strain $\left(\varepsilon_{2}\right)$ was substantial, from 26000 to $4000 \mu \varepsilon$ when the specimen was tested at $120{ }^{\circ} \mathrm{C}$. The failure by slippage was the same of the dry fabric FRCM. On the other hand, the FRCM systems with uncoated (dry) fabric only experienced a drop of $11 \%$ in tensile strength when subjected to 120 ${ }^{\circ} \mathrm{C}$.

Table 5. Tensile test results [according to AC434, Annex A]

\begin{tabular}{|c|c|c|c|c|c|c|c|c|c|}
\hline Mortar & Fabric & $\begin{array}{c}\text { Temp. } \\
\left({ }^{\circ} \mathrm{C}\right)\end{array}$ & & $\begin{array}{c}\mathrm{E}_{2} \\
(\mathrm{GPa}) \\
\end{array}$ & $\begin{array}{c}\% \\
\text { change } \\
\mathrm{E}_{2}{ }^{*} \\
\end{array}$ & $\begin{array}{c}\sigma_{\mathrm{u}} \\
(\mathrm{MPa})\end{array}$ & $\begin{array}{c}\% \\
\text { change } \\
\sigma_{\mathrm{u}}{ }^{*} \\
\end{array}$ & $\begin{array}{c}\varepsilon_{2} \\
(\%) \\
\end{array}$ & $\begin{array}{l}\text { Fail. } \\
\text { mode }\end{array}$ \\
\hline \multirow{12}{*}{$\begin{array}{l}\text { Mortar- } \\
45\end{array}$} & \multirow{6}{*}{ Dry } & \multirow{2}{*}{20} & Average & - & \multirow{2}{*}{ - } & 986 & \multirow{2}{*}{-} & 0.010 & \multirow{2}{*}{$S$} \\
\hline & & & $\operatorname{COV}(\%)$ & - & & 9 & & 30 & \\
\hline & & \multirow{2}{*}{80} & Average & - & \multirow{2}{*}{ - } & 955 & \multirow{2}{*}{-3} & 0.012 & \multirow{2}{*}{$S$} \\
\hline & & & $\operatorname{COV}(\%)$ & - & & 11 & & 18 & \\
\hline & & \multirow{2}{*}{120} & Average & - & \multirow{2}{*}{ - } & 874 & \multirow{2}{*}{-11} & 0.008 & \multirow{2}{*}{$S$} \\
\hline & & & $\operatorname{COV}(\%)$ & - & & 12 & & 12 & \\
\hline & \multirow{6}{*}{ HS } & \multirow{2}{*}{20} & Average & 49 & & 1366 & \multirow[b]{2}{*}{ - } & 0.026 & \multirow{2}{*}{$\mathrm{F} / \mathrm{S}$} \\
\hline & & & $\operatorname{COV}(\%)$ & 25 & & 18 & & 22 & \\
\hline & & \multirow{2}{*}{80} & Average & 36 & \multirow{2}{*}{-27} & 411 & \multirow{2}{*}{-70} & 0.012 & \multirow{2}{*}{ S } \\
\hline & & & $\operatorname{COV}(\%)$ & 14 & & 6 & & 10 & \\
\hline & & \multirow{2}{*}{120} & Average & 35 & \multirow{2}{*}{-29} & 407 & \multirow{2}{*}{-70} & 0.004 & \multirow{2}{*}{ S } \\
\hline & & & $\operatorname{COV}(\%)$ & 17 & & 10 & & 22 & \\
\hline
\end{tabular}

S) Slippage of the fabric within the matrix

F) Fabric failure

*Percentage change relative to room temperature conditions $\left(20^{\circ} \mathrm{C}\right)$ 


\subsection{SEM analysis}

The interface between coated carbon yarn and surrounding mortar was observed by SEM (at a magnification ranging from 30x to 50x), on samples cured at room temperature (Figure 7a) and after being tested at $120^{\circ} \mathrm{C}$ (Figure $7 b$ ).

The post-tensile test detachment of the yarn from the matrix resulting in the consequent slippage of the fabric within the mortar is visible. The coated yarn is free to slip within the mortar after the resin has exceeded the $T_{g}$, while the sand grains used to improve the interface bond remain attached to the cementitious matrix.
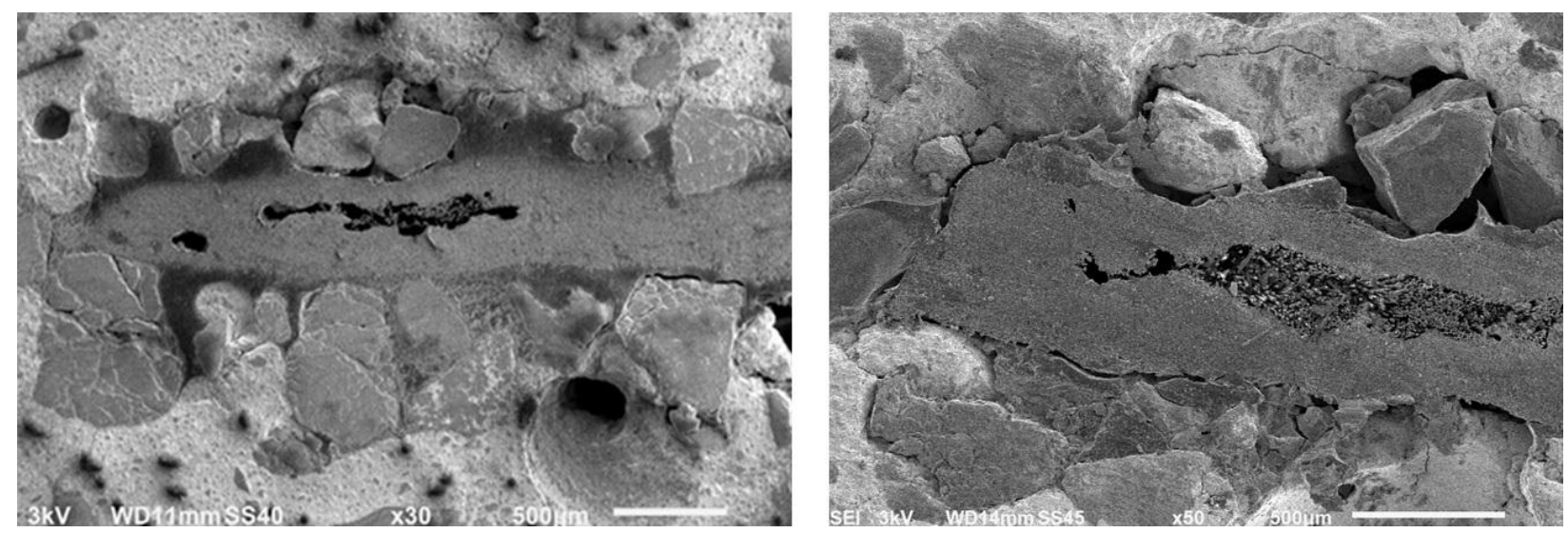

Figures 7. SEM analysis at yarn-matrix interface before (a) and after (b) tensile test

\subsection{Double shear bond test results}

Double shear tests confirmed the undesirable effect of the enhancement of coating the FRCM fabric on the mechanical properties of the FRCM system when subjected to high temperature conditions. Results of the maximum peak load and relative displacements are reported in Table 6. At room temperature, the FRCM enhanced with coated fabric had higher shear bond strength than the dry counterpart; however, when exposed to high temperatures the bond at the fabricmortar interface for fibers with epoxy coating is reduced as seen in the displacement-load graph shown in Figure 8. The reduction in both load carrying capacity and displacement of the fibercoated FRCM system is due to the exposure to $120{ }^{\circ} \mathrm{C}$ temperature.

Table 6. Double shear test results [according to RILEM TC250-CSM]

\begin{tabular}{|c|c|c|c|c|c|c|c|}
\hline Mortar & Fabric & $\begin{array}{c}\text { Temp } \\
\left({ }^{\circ} \mathrm{C}\right)\end{array}$ & & $\begin{array}{c}\text { Peak Load } \\
\text { (per side) } \\
f_{\max } \\
(\mathrm{N}) \\
\end{array}$ & $\begin{array}{c}\% \\
\text { change } \\
f_{\max }\end{array}$ & $\begin{array}{l}\text { Slip at } \\
\text { peak } \\
\text { load } \\
(\mathrm{mm}) \\
\end{array}$ & $\begin{array}{c}\text { Peak stress in } \\
\text { the textile } \\
\sigma_{f}=f_{\max } / A_{f} \\
(\mathrm{MPa})\end{array}$ \\
\hline \multirow{8}{*}{$\begin{array}{c}\text { Mortar- } \\
45\end{array}$} & \multirow{4}{*}{ Dry } & \multirow{2}{*}{20} & Average & 1976 & \multirow[b]{2}{*}{ - } & 2.89 & 633 \\
\hline & & & $\operatorname{COV}(\%)$ & 10 & & 5 & 10 \\
\hline & & \multirow{2}{*}{120} & Average & 2094 & \multirow{2}{*}{+6} & 3.37 & 671 \\
\hline & & & $\operatorname{COV}(\%)$ & 9 & & 8 & 9 \\
\hline & \multirow{4}{*}{ HS } & \multirow{2}{*}{20} & Average & 2503 & \multirow{2}{*}{ - } & 4.18 & 802 \\
\hline & & & $\operatorname{COV}(\%)$ & 2 & & 2 & 2 \\
\hline & & \multirow{2}{*}{120} & Average & 961 & \multirow{2}{*}{-62} & 3.12 & 308 \\
\hline & & & $\operatorname{COV}(\%)$ & 8 & & 6 & 8 \\
\hline
\end{tabular}


A comparison between FRCM specimens exposed and not to temperature, both tested at $20^{\circ} \mathrm{C}$, is shown in Figure 9. Results reported in Table 7 show that the maximum peak load is almost the same, even after the specimens have been exposed to $120{ }^{\circ} \mathrm{C}$ for 60 minutes. The decrease of the peak load is of $7 \%$, while the ultimate slip remained unchanged. This study showed that the use of FRCM reinforced with coated fabric is able to maintain a good shear-bond resistance even after being exposed to high temperature conditions. Temperatures up to $120^{\circ} \mathrm{C}$ are not able to decompose the selected coating and after cooling the epoxy regains its integrity.

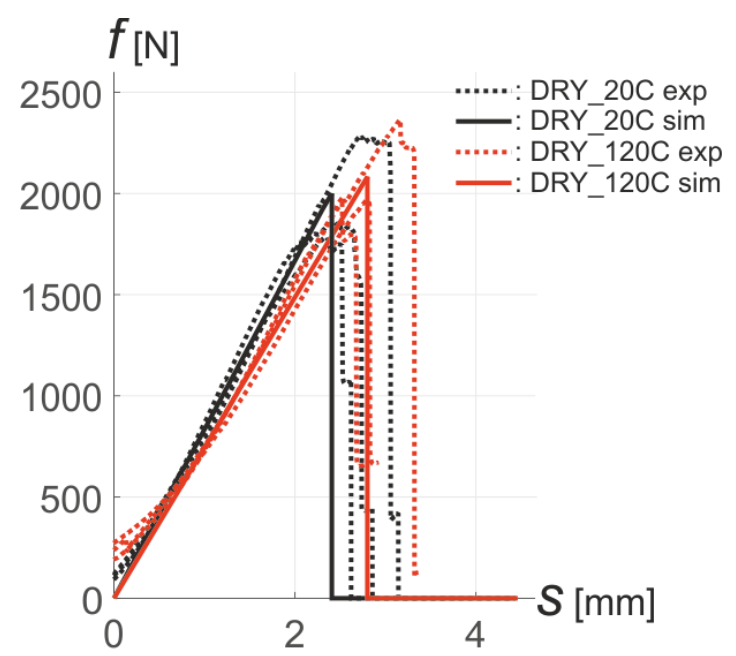

( a )

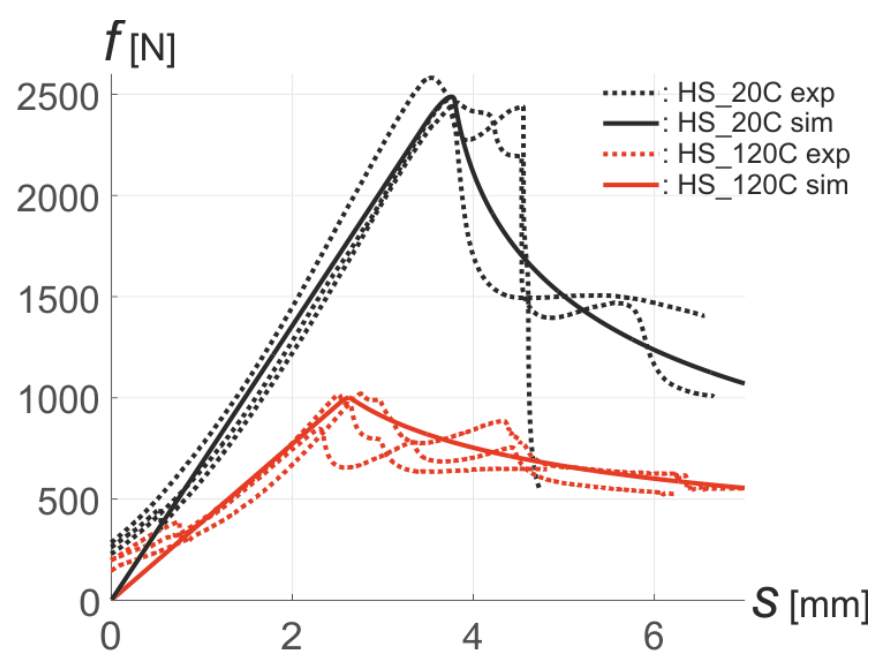

( b )

Figure 8. Double shear bond test: comparison between FRCM reinforced with dry and coated (HS) fabrics at different temperatures

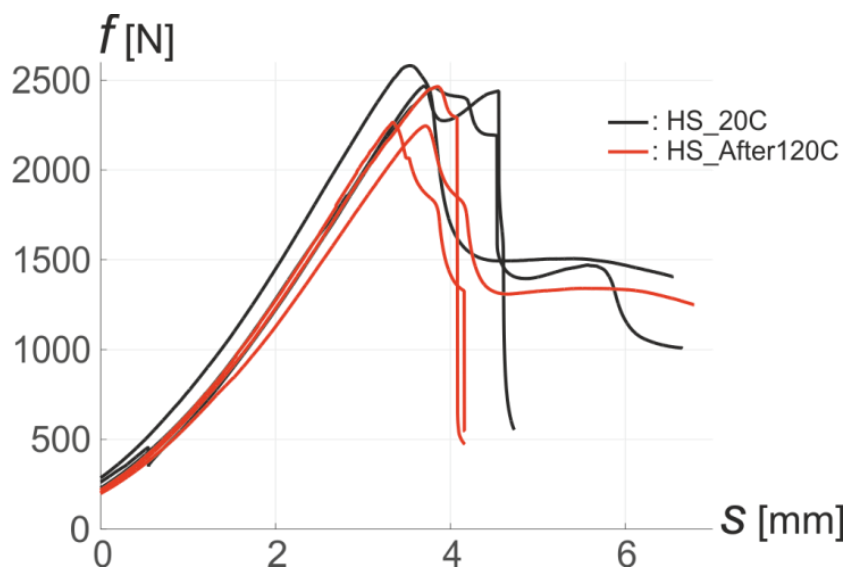

Figure 9. Double-shear bond test: FRCM residual performance after exposure to high temperature $\left(120^{\circ} \mathrm{C}\right)$ for 60 minutes 
Table 7. Double shear test results after exposure to $120^{\circ} \mathrm{C}$ [according to RILEM TC250-CSM]

\begin{tabular}{|c|c|c|c|c|c|c|c|}
\hline Mortar & Fabric & $\begin{array}{c}\text { Temperature } \\
\text { of testing } \\
\left({ }^{\circ} \mathrm{C}\right)\end{array}$ & & $\begin{array}{c}\text { Peak Load } \\
\text { (per side) } \\
f_{\max } \\
(\mathrm{N})\end{array}$ & $\begin{array}{c}\% \\
\text { change } \\
f_{\max }\end{array}$ & $\begin{array}{l}\text { Slip at } \\
\text { peak } \\
\text { load } \\
(\mathrm{mm})\end{array}$ & $\begin{array}{c}\text { Peak stress } \\
\text { in the textile } \\
\sigma_{f}=f_{\max } / A_{f} \\
(\mathrm{MPa})\end{array}$ \\
\hline \multirow{4}{*}{$\begin{array}{c}\text { Mortar- } \\
45\end{array}$} & \multirow{4}{*}{ HS } & \multirow{2}{*}{20} & Average & 2503 & & 4.18 & \multirow[t]{2}{*}{802} \\
\hline & & & $\operatorname{COV}(\%)$ & 2 & & 2 & \\
\hline & & 20 & Average & 2325 & \multirow[b]{2}{*}{-7} & 4.19 & \multirow[t]{2}{*}{745} \\
\hline & & Aft.exposure & $\operatorname{COV}(\%)$ & 4 & & 4 & \\
\hline
\end{tabular}

\section{Numerical simulations and comparisons with experimental results}

\subsection{Parameters setting}

We consider the simplified two-dimensional geometry of Fig. 5f, discussed in Sect. 3.1. Matrix and yarn domains are discretized by three-nodes triangular finite elements as shown in Fig. 10a. Young's modulus, Poisson's ratio and tensile strength of the two materials have been assigned as reported in Table 1 and Table 3. Since the aggregates in the cementitious mortar have a size of about 1-2 $\mathrm{mm}$, we assign $B=5 \mathrm{~mm}$ to the thickness of the process zone. Indeed, according to [47, 31 ], the characteristic thickness of the damage localization zone is typically 2-3 times the size of the constituent grains. Given $E, \sigma_{e}$ and $B$, parameters $d$ and $l_{m}$ are determined from $(5)_{1,2}$.

Different constitutive parameters are assigned to the matrix-fiber interface to distinguish dry (DRY) and coated with sand (HS) carbon fabrics at different temperature exposure. These parameters have been assigned following an inverse approach, starting from global double shear bond curves (Fig. 8) and deriving the interface constitutive parameters. For sake of simplicity, we assume $k=k_{x}=k_{y}$ in the elastic tensor $\mathbf{k}$ in (6). Since experiments exhibit temperaturedependent mechanical responses, the interface constitutive parameters vary with temperature $T$, that is, $k=k(T), \tau_{e}=\tau_{e}(T)$ and $q=q(T)$. Parameters $k$ and $\tau_{e}$ define slope and extension of the $d-\tau_{e}$ elastic branch, while $q$ describes the shape of the post-elastic branch. We recall that $a$ in (6) is determine from $k$ and $\tau_{e}$ by formula (9). A schematic description of the procedure followed to fix the interface material parameters is proposed in the Appendix.

Interface parameters - DRY carbon fabrics. To reproduce the brittle behavior observed in experiments (see Fig. 8a), we assign $q=-2$, whatever the temperature $T$. In this way, the interface brutally breaks when the limit elastic shear stress $\tau_{e}$ is reached (see Fig. 6). For $k$ and $\tau_{e}$, we fix $k(20)=1.6 \mathrm{~N} / \mathrm{mm}^{3}, k(120)=1.2 \mathrm{~N} / \mathrm{mm}^{3}$, and $\tau_{e}(20)=\tau_{e}(120)=1.7 \mathrm{MPa}$ (see Fig. 10b). For increasing $T, k$ reduces, while $\tau_{e}$ maintains fixed.

Interface parameters - HS carbon fabrics. Temperature considerably affects the parameter values in the case of coated fabric, since the mechanical characteristics of the epoxy coating highly depends on thermal conditions. We assume $k(20)=1.0 \mathrm{~N} / \mathrm{mm}^{3}, \tau_{e}(20)=1.9 \mathrm{MPa}$, and $k(120)=0.4 \mathrm{~N} / \mathrm{mm}^{3}, \tau_{e}(20)=0.75 \mathrm{MPa}$ (see Fig. 10b). Thus, temperature considerably reduces both the elastic coefficient and the shear strength. Since the experimental curves of Fig. $8 \mathrm{~b}$ exhibit a pronounced post-elastic softening phase, curves of Fig. 6 suggest of choosing values of $q$ within the range $(-2,2)$. At $T=20^{\circ} \mathrm{C}$, we set $q=0.3$, which accounts for a residual shear strength 
$\tau_{r}=0.68 \mathrm{MPa}$ at the shear displacement $\delta_{r}=4 \delta_{e}=7.6 \mathrm{~mm}$ (black dot in Fig. $10 \mathrm{~b}$ ). At $T=120^{\circ} \mathrm{C}$, we set $q=0.7$. In such a way, at the shear displacement $\delta_{r}=4 \delta_{e}=7.5 \mathrm{~mm}$, the residual shear strength is $\tau_{r}=0.39 \mathrm{MPa}$ (red dot in Fig. 10b).

For both the HS and DRY samples, we assume $l_{s}=1 \mathrm{~mm}$.

\subsection{Results and comparisons}

Simulations are conducted by increasing the vertical displacement $\delta$, and computing the corresponding vertical normal stress $\sigma_{y}$ on the yarn upper side. These quantities are related to the overall displacement $s$ and force $f$ (see Fig.8), measured in the experiments and reported in the curves of Fig. 8, by means of the relations

$$
s=\delta+\frac{h_{y}}{E_{f}} \sigma_{y}, \quad f=3 \sigma_{y} A,
$$

where $h_{y}=310 \mathrm{~mm}$ is the length of the fabric part which connects the sample to the experimental pulling device, $E_{f}$ is the yarn Young's modulus, and $A$ is the yarn cross-section area. In $(17)_{1}$, the second term in the right-hand side is the displacement due to the elastic deformation of the fabric, and, in (17) $)_{2}$, the factor 3 accounts for the number of yarns in a fabric.

The force-displacement curves given by the numerical simulations are drawn in Fig. 8 (solid line) and compared with the experimental curves (dotted line).

Results - DRY carbon fabrics. As expected, DRY_20C and DRY_120C samples exhibit a brittle behavior. The matrix-yarn interface experiences debonding when the limit shear stress $\tau_{e}$ is attained, while the cementitious matrix never damages. The evolution of the damage $\alpha$ and shear stress $\tau_{y}$ for increasing $\delta$ is described in Fig. 11. The $\delta$ - $f$ curves plotted in Fig. 11a exhibit steep and short softening branches, concluding with drops. Profiles of $\alpha$ and $\tau_{e}$ on the interface of the DRY_20C sample are plotted in Figs. 11b and 11c for different values of $\delta$ within the softening phase (dotted points in the enlargement of Fig. 11a). Damage forms in the upper part of the interface, when the limit shear stress $\tau_{e}$ is reached. Then it evolves downward, for almost a half of the interface. Finally, a brutal failure occurs, producing the total detachment of the yarn from the matrix. Fig. 11c shows that $\tau_{y}$ is equal to $\tau_{e}$ at the tip of the damaged zone, and it decreases within the damaged zone as $\alpha$ increases, being null there where $\alpha=0$.

Results - HS carbon fabrics. Even in HS samples (with coated carbon fabrics), damage concentrates at the matrix-fiber interface, and the cementitious matrix maintains undamaged. Both at $T=20^{\circ} \mathrm{C}$ and $120^{\circ} \mathrm{C}$, the $s-f$ curves of Fig. 8 present softening branches which accurately fit the experimental curves. Damage evolution at the interface is described in Fig. 12 where snapshots of $\alpha$ and $\tau_{y}$ are represented at different values of $s$ corresponding to the softening regime. In the two simulations, damage forms in the upper side of the interface when $\tau_{y}$ reaches the maximum value $\tau_{e}$, and rapidly spreads all over the interface. Increasing $s$, damage almost homogeneously increases all over the interface, and, at $s=0.7 \mathrm{~mm}$, the final damage values $\alpha_{f}=0.64$ and 0.60 are reached at the interface of the HS_20C and HS_120C samples, respectively. The interface at the end of the experiments is not completely damaged, being $\alpha_{f}$ quite smaller than 1, and this provides residual strength sources to the system. A residual strength is also observed in the experiments. Indeed the curves of Fig. $8 \mathrm{~b}$ present non-null values of $f$ at their end. This strengthening at large displacement may be due to the augmented frictional effect produced by the coating. 


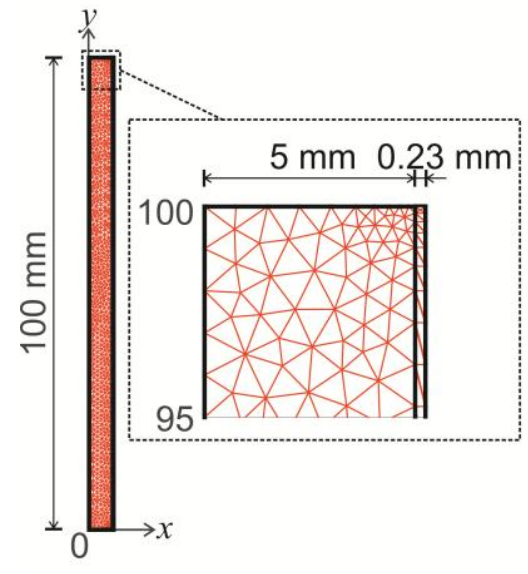

( a )

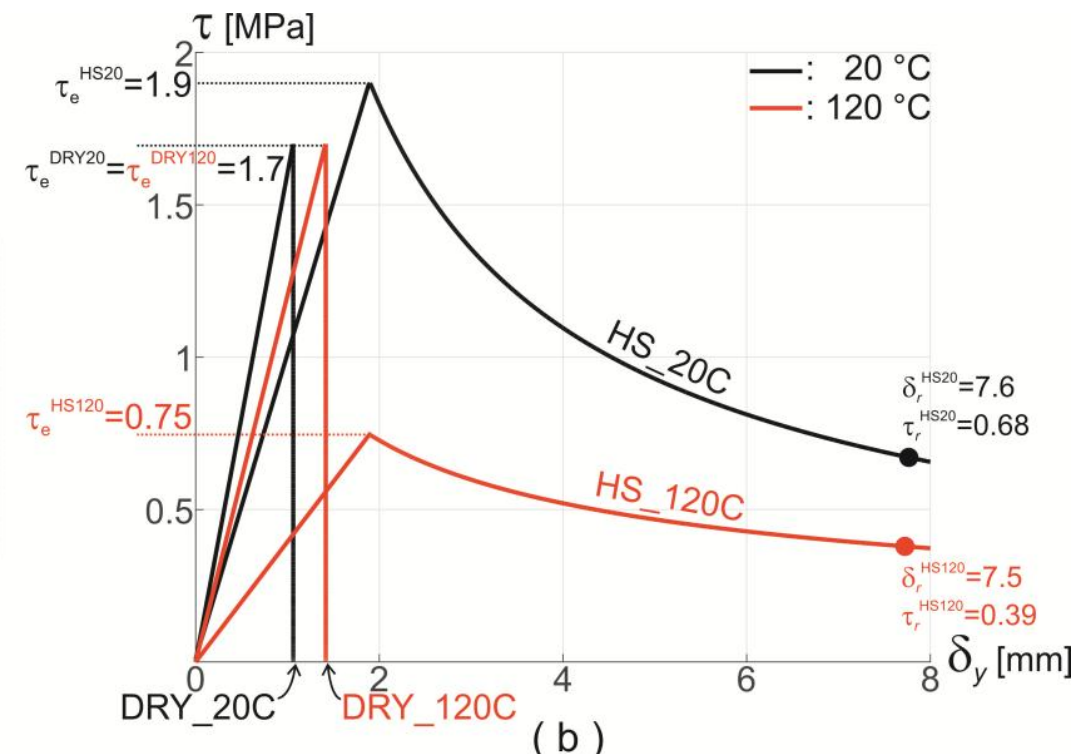

Figure 10. (a) Mesh. (b) $\delta_{y}$ - $\tau$ curves for the calibration of the interface damage parameters.
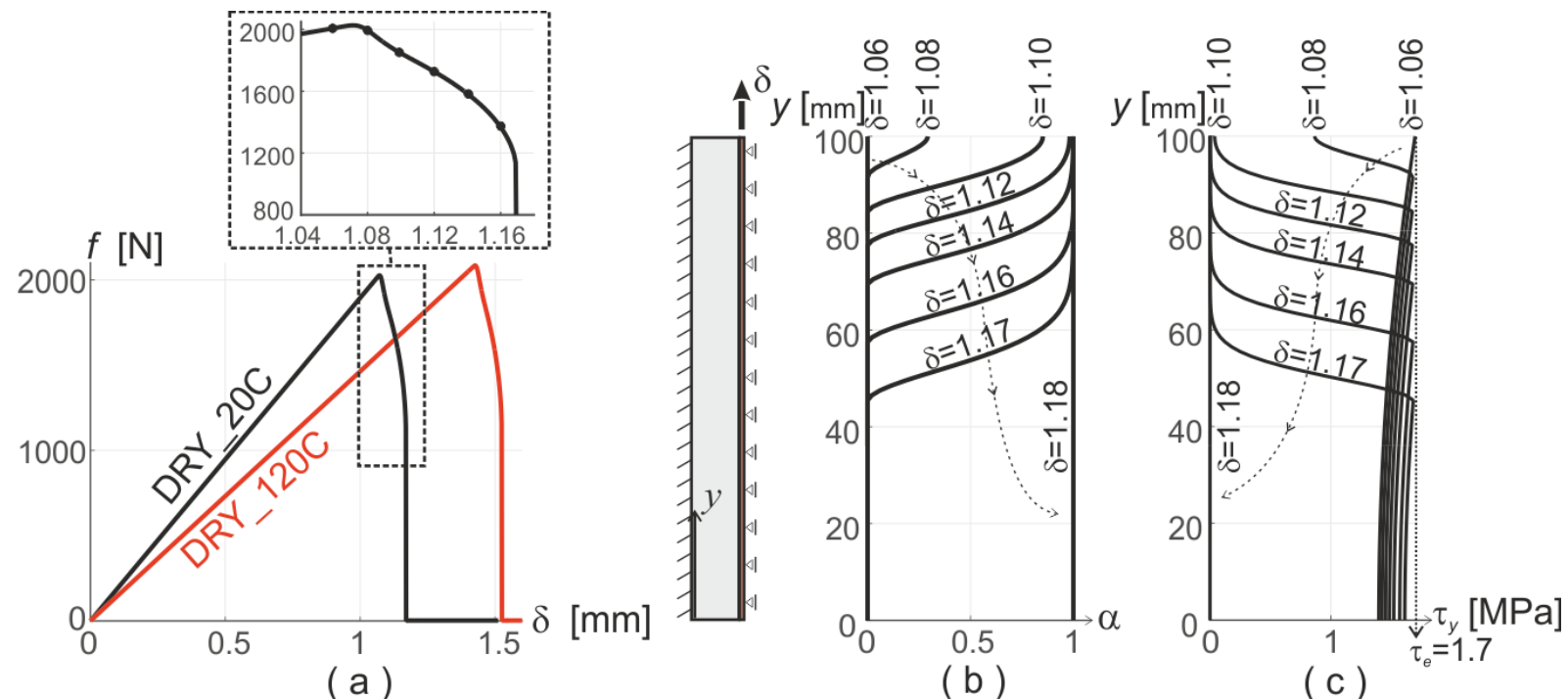

Figure 11. (a) Displacement $\delta$-force $f$ curves for the DRY_20C and DRY_120C samples. Profiles of damage $\alpha(b)$ and shear stress $\tau(c)$ at the interface of the DRY_20C sample for different values of $\delta$. 


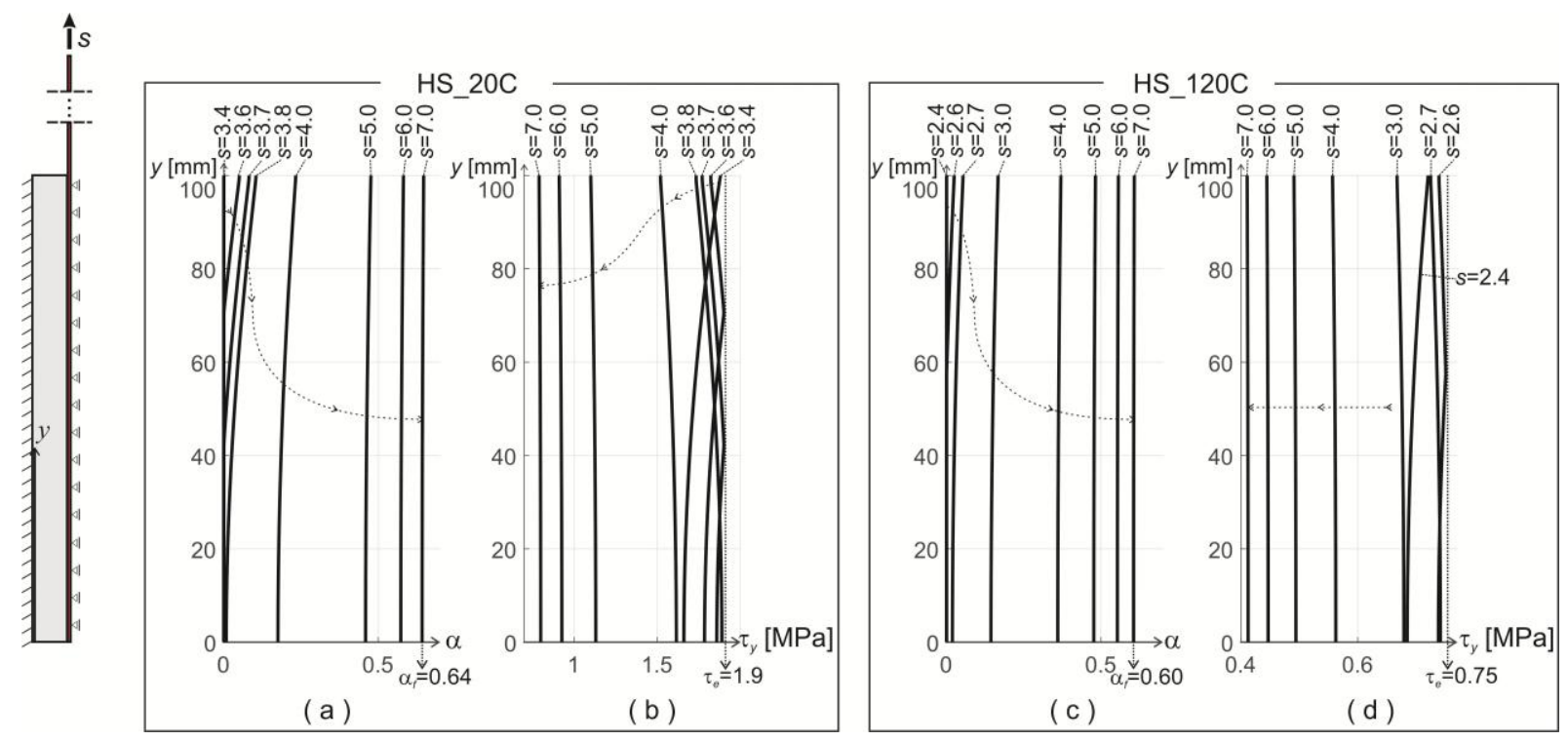

Figure 12. Profiles of damage $\alpha$ and shear stress $\tau$ at the interface of the $H S \_20 C(a, b)$ and $H S \_120 C(c, d)$ samples for different values of $s[\mathrm{~mm}]$.

\section{Conclusions}

Based on the experimental results for specific materials presented herein, the following is concluded:

- FRCM systems can provide high temperature compatibility retaining mechanical performance when exposed to $120{ }^{\circ} \mathrm{C}$ depending on the type of fabric reinforcement used.

- FRCM reinforced with dry (uncoated) fabric seemed not to be influenced by the temperature conditions, maintaining an adequate resistance and bond to the substrate even when exposed to $120{ }^{\circ} \mathrm{C}$ for 100 minutes, when the temperature at the fabric to mortar interface was between 90 and $110^{\circ} \mathrm{C}$.

- FRCM reinforced with coated fabric showed drastic differences depending on the temperature of testing. The reduction in the FRCM ultimate tensile capacity was of $70 \%$ when tested at $80{ }^{\circ} \mathrm{C}$. Same reduction was observed at $120{ }^{\circ} \mathrm{C}$. Double shear bond tests showed a reduction in the ultimate peak load of $61 \%$ at $120^{\circ} \mathrm{C}$.

- FRCM with coated fabrics preheated to $120{ }^{\circ} \mathrm{C}$ for 60 minutes and tested at room temperature showed smaller differences in terms of mechanical performances. The decrease of the peak load was of $7 \%$ and no differences were detected in the ultimate slip. These results showed that the coating is able to maintain a good adhesion with the mortar when cooled down after being exposed to $120{ }^{\circ} \mathrm{C}$ for 60 minutes. Therefore, FRCM reinforced with coated carbon fabric can still maintain its structural function after the exposure to high temperatures, upon to $120^{\circ} \mathrm{C}$.

- Numerical simulations confirmed that for any temperature and fabric type, the main failure mechanism is by fabric slippage within the cementitious matrix.

- Double shear simulations on FRCM reinforced with DRY fabrics exhibit a top-down detachment at the matrix-fibers interface after reaching the maximum peak load. The 
damage development occurs in the first $50 \mathrm{~mm}$ of the bonded area and quickly evolves along the entire bond length up to failure.

- In presence of coated fabrics, the detaching mechanism is different from that observed in DRY fabrics. Indeed, damage almost homogeneously starts and slowly develops at the whole fabric-matrix interface. At the end of the softening phase, the interface is only partially damaged, and it is still able of bearing some shear stresses. This final residual strength accounts for material frictional sources.

- Although there are few results in literature regarding the FRCM behavior when exposed to high temperature conditions, some qualitative comparisons can be made. As experienced by Trapko, FRCMs have proven to behave better than FRP when exposed to high temperatures, maintaining an adequate load bearing capacity up to $80{ }^{\circ} \mathrm{C}$ [17]. The use of coated fabrics improved the FRCM mechanical performances but can be a limitation if the temperature within the FRCM exceeds the coating $\mathrm{T}_{\mathrm{g}}$. However, coated fabrics are able to recover the load bearing capacity when cooled down after being exposed to high temperatures (at least up to $120^{\circ} \mathrm{C}$ for 60 minutes of exposure) and this result is in line with the experiments conducted by Silva and co-workers [22].

We conclude that the phase-field variational approach has revealed a promising approach for the study of the failure mechanisms in FRCM systems. Indeed, the proposed model, despite its geometrical simplicity, has shown great predictive capabilities, accurately reproducing the experimental results. A further advantage of the model is that it only depends on few parameters directly related to specific materials properties, which are easily measurable from experiments. Here they are determined following an inverse procedure, i.e., assigning those values that allow for a better fitting of the experimental response curves.

The use of FRCM as externally bonded reinforcement could be a valid solution to be adopted in case of applications were high temperature service conditions is a possible scenario. However, further tests on the mechanical behavior and durability of FRCM systems when exposed to these particular environmental conditions are necessary to better understand the phenomenon and provide guidelines for a proper design approach.

\section{ACKNOWLEDGEMENTS}

The authors gratefully acknowledge the financial support provided by the National Science Foundation (NSF) under grant IIP-1439543, Fondazione Marche and ISSNAF. Materials were provided by BASF Company and ECTSystem srl. 


\section{APPENDIX}

The procedure used to fix the model parameters is schematically drawn, and some examples are presented.

Parameters setting procedure. Assume that:

(i) the experimental force-displacement curve is given. Here, as an example, the curve of Fig. 13 is considered, which is an HS_20 curve among the three HS_20 curves of Fig. $8 \mathrm{~b}$;

(ii) the 2D geometry is defined according to the criteria given in Sect. 3.1;

(iii) Young's modulus and Poisson's ratio of matrix and yarn $E_{m}, v_{m}, E_{f}, v_{f}$ are given;

(iv) splitting tensile strength $\sigma_{e}$ of the matrix is known;

(v) size $B$ of the process zone in the mortar is assigned (typically 2-3 times the size of the cementitious aggregates);

(vi) the internal length $l_{s}$ in (6) is assumed equal to $1 \mathrm{~mm}$; being related to the sliding process zone, its value is quite uncertain and thus it is fixed arbitrary. However, notreported simulations have shown that different values do not modify the results.

The remaining constitutive parameters are deduced as follows:

1. the coefficients $d$ and $l_{m}$ in the matrix damage energy are determined from formulas $(5)_{1,2}$;

2. the maximum elastic shear stress $\tau_{e}$ of the interface (see Fig. 6) is estimated from the maximum elastic force $f_{e}$ of Fig. 13 by the formula

$$
\tau_{\mathrm{e}}=\frac{1}{3 h b_{3}} \frac{\beta}{(\beta+1)} f_{e},
$$

obtained from (1) and (17) $)_{2}$, where $h$ and $b_{3}$ are the geometrical lengths of Fig. 5;

3. the elastic coefficient of the interface springs is $k=\tau_{e} / \delta_{e}$ (see Fig. 6), which, use (17) 1 , rewrites

$$
k=\tau_{\mathrm{e}} /\left(s_{e}-\frac{h_{y}}{3 A} \frac{f_{e}}{E_{f}}\right),
$$

where quantities on the right-hand side are known ( $\tau_{e}$ is determined at point $1, f_{e}$ and $s_{e}$ are deduced from the experimental response curve (point i), $E_{f}$ is known (point iii), and $h_{y}$ and $A$ are assigned geometrical quantities (point ii)). Formula (2A) is used to set $k$;

4. once $\tau_{e}$ and $k$ are estimated, coefficient $a$ in (6) is determined from (9);

5. finally, the exponent $q$ in (6), which controls the slope of the softening branch, is chosen via a fitting procedure, aimed at reproducing the experimental softening branch (Fig. 13).

Examples. Some examples are proposed, where the above procedure of parameters setting is followed.

We assume the experimental curve of Fig. 13 (point i), the geometry defined in Sect. 3.1 (point ii), the constitutive parameters of Tables 1 and 3 (points iii and iv), and $B=5 \mathrm{~mm}$ (point v). 
Following prescriptions given at points $1-4$, we obtain: $d=0.0011 \mathrm{MPa}, l_{m}=1.77 \mathrm{~mm}$ (point 1); $\tau_{e}=1.9 \mathrm{MPa}$ (point 2); $k=1 \mathrm{MPa} / \mathrm{mm}$ (point 3); $a=3.61 \mathrm{MPa} \mathrm{mm}$ (point 4). For the softening exponent $q$ of point 5, different values are considered in order to show the parameter influence on the post-elastic stress-softening behaviour. Numerical response curves corresponding to different $q$ are drawn in Fig. 13. The slope of the softening branch reduces as $q$ increases. In this case, the curve for $q=0.3$ allows for the best matching the experimental softening branch.

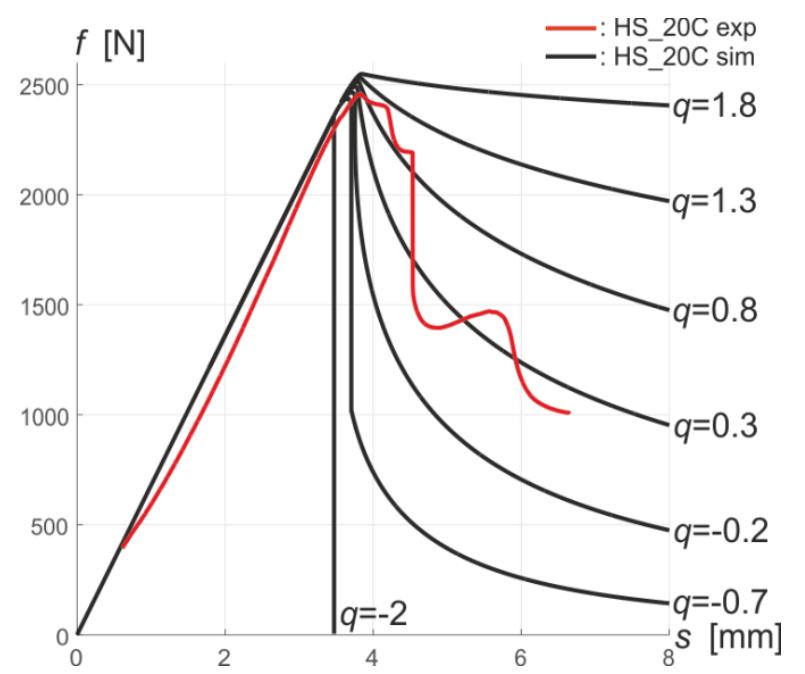

Figure 13. Force-displacement curves for different values of $q$.

\section{REFERENCES}

[1] Foster SK, Bisby L. High temperature residual properties of externally-bonded FRP systems. American Concrete Institute. Vol. ACI-SP230 2005;7:1235-1252.

[2] Cao S, Wu Z, Wang X. Tensile properties of CFRP and hybrid FRP composites at elevated temperatures. Journal of Composite Materials 2009;43(4):315-330.

[3] Burke PJ, Bisby L, Green M. Effects of elevated temperature on near surface mounted and externally bonded FRP strengthening systems for concrete. Cement \& Concrete Composites 2013;35:190-199.

[4] Cao S, Wu Z, Wang X. Tensile properties of CFRP and hybrid FRP composites at elevated temperatures. Journal of Composite Materials 2009;43(4):315-330.

[5] Sgarito L. Analisi sperimentale degli effetti di temperature elevate sul comportamento strutturale dei rinforzi in FRP. Tesi di Laurea. Università di Bologna, 2006-2007.

[6] Chowdhury EU, Eedson R, Bisby LA, Green M, Benichou N. Mechanical Characterization of Fibre Reinforced Polymers Materials at High Temperature. Fire Technology 2011;47(4):10631080.

[7] Al-Salloum Y, Elsanadedy HM, Abadel AA. Behavior of FRP-confined concrete after high temperature exposure. Construction and Building Materials 2011;25:838-850.

[8] Chowdhury EU, Bisby LA, Green MF, Kodur VKR. Investigation of insulated FRP-wrapped reinforced concrete columns in fire. Fire Safety Journal 2007;42:452-460. 
[9] Bisby L, Williams B, Kodur V, Green M, Chowdhuty E. Fire insulation schemes for FRPstrengthened concrete slabs. Composites Part A: applied science and manufacturing 2006;37:1151-1160.

[10] Silva FA, Rambo DAS, Filho RDT, Gomes O. Effect of elevated temperatures on the mechanical behavior of basalt textile reinforced refractory concrete. Materials and design 2015;65:24-33.

[11] Nanni A. FRCM strengthening - a new tool in the concrete and masonry repair toolbox. Concrete International 2012:34(4):43-49.

[12] Pellegrino C, D’Antino T. Experimental behaviour of existing precast prestressed reinforced concrete elements strengthened with cementitious composites. Composites Part B: Engineering 2013;55:31-40.

[13] Bisby L, Stratlford T, Smith J, Halpin S. FRP versus fiber reinforced cementitious mortar systems at elevated temperature. 10th International Symposium on Fiber-Reinforced Polymer Reinforcement for Concrete Structures American Concrete Institute, Tampa, FL (USA), ACI Special Publication 2011;2(275):863-881.

[14] Bisby L, Roy EC, Ward M, Stratlford TJ. Fibre reinforced cementitious matrix systems for fire-safe flexural strengthening of concrete: Pilot testing at ambient temperature. Advanced Composites in Construction, ACIC 2009 - Proceedings of the 4th International Conference on Advanced Composites in Construction 2009:449-460.

[15] Verbruggen S, Aggelis DG, Tysmans T, Wastiels J. Bending of beams externally reinforced with TRC and CFRP monitored by DIC and AE. Composite Structures 2014;112(1):113-121.

[16] Corinaldesi V, Donnini J, Mazzoni G. Experimental study of adhesion between FRCM and masonry support. Key Engineering Materials 2015;624:189-196.

[17] Trapko T. The effect of high temperature on the performance of CFRP and FRCM confined concrete elements. Composites Part B: Engineering 2013;54:138-145.

[18] Donnini J, Corinaldesi V, Nanni A. Mechanical properties of FRCM using carbon fabrics with different coating treatments. Composites Part B 2016;88:220-228.

[19] Yin, S., Xu, S., Li, H., "Improved mechanical properties of textile reinforced concrete thin plate," Journal Wuhan University of Technology, Material Science Edition 2013;28(1):92-98.

[20] Corinaldesi V, Donnini J, Nanni A. FRCM mechanical properties using carbon fabrics with different coating treatments. ACI Special Publications SP 305, Publisher: American Concrete Institute, 2015;8:1-12.

[21] $\mathrm{Xu} \mathrm{S}$, Shen L, Wang J, Fu Y. High temperature mechanical performance and micro interfacial adhesive failure of textile reinforced concrete thin-plate. Journal of Zhejiang University-SCIENCE A (Applied Physics \& Engineering) 2014;15(1):31-38.

[22] Silva FA, Butler M, Hempel S, Toledo RD, Mechtcherine V. Effects of elevated temperatures on the interface properties of carbon textile-reinforced concrete. Cement \& Concrete Composites 2014;48:26-34.

[23] Krüger M, Reinhardt HW. In: Wolfgang Brameshuber, editor. Fire resistance. Report 36: textile reinforced concrete - state-of-the-art report of RILEM technical committee 201-TRC. Bagneux: Rilem publications S.A.R.L 2006;6:83-218.

[24] Michels J, Motovalli M. Structural strengthening of concrete with fiber reinforced cementitious matrix (FRCM) at ambient and elevated temperature-recent investigations in Switzerland. Advances in Structural Engineering 2014;17(12):1785-1799. 
[25] Carozzi FG, Poggi C. Mechanical properties and debonding strength of Fabric Reinforced Cementitious Matrix (FRCM) systems for masonry strengthening. Composites Part B: Engineering 2015;70:215-30.

[26] D`Ambrisi A, Feo L, Focacci F. Experimental analysis on bond between PBO-FRCM strengthening materials and concrete. Composites Part B: Engineering 2013;44(1):524-32.

[27] Hartig J, Häußler-Combe U, Schicktanz K. Influence of bond properties on the tensile behaviour of Textile Reinforced Concrete. Cement \& Concrete Composites 2008;30:898-906.

[28] Bourdin B, Francfort GA, Marigo JJ. Numerical experiments in revisited brittle fracture, J. Mech. Phys. Solids 2000;48(4):797-826.

[29] Francfort GA, Marigo JJ. Revisiting brittle fracture as an energy minimization problem, J. Mech. Phys. Solids 1998;46(8):1319-1342.

[30] Del Piero G, Lancioni G, March R. A variational model for fracture mechanics: numerical experiments. J. Mech. Phys. Solids 2007;55:2513-2537.

[31] Lancioni G, Royer-Carfagni G, The variational approach to fracture mechanics. A practical application to the French Panthéon in Paris, J. Elast 2009;95:1-30.

[32] Amor H, Marigo JJ, Maurini C. Regularized formulation of the variational brittle fracture with unilateral contact: numerical experiments, J. Mech. Phys. Solids 2009;57:1209-1229.

[33] Freddi F, Royer Carfagni G, Regularized variational theories of fracture: a unified approach, J. Mech. Phys. Solids 2010;58:1154-1174.

[34] Pham K, Amor H, Marigo JJ, Maurini C. Gradient damage models and their use to approximate brittle fracture, Int. J. Damage Mech 2011;20:618-652.

[35] Del Piero G. "A variational approach to fracture and other inelastic phenomena", J. Elast., 2013;112:3-73.

[36] Del Piero G, Lancioni G, March R. A diffuse cohesive energy approach to fracture and plasticity: the one-dimensional case. J. Mech. Mater. Struct. 2013;8(2-4):109-151.

[37] Lancioni G, Modeling the response of tensile steel bars by means of incremental energy minimization, J. Elast 2015;121(1):25-54.

[38] Lancioni G, Yalcinkaya T, Cocks A. Energy-based non-local plasticity models for deformation patterning, localization and fracture, Proceedings of the Royal Society A 2015;471.

[39] Lancioni G, Zitti G, Yalcinkaya T. Rate-independent deformation patterning in crystal plasticity, Key Engineering Materials 2015;651(653):944-949.

[40] ASTM C109/C109M. Standard Test Method for Compressive Strength of Hydraulic Cement Mortars; 2016.

[41]ASTM C496/C496M. Standard Test Method for Splitting Tensile Strength of Cylindrical Concrete Specimens; 2011.

[42] ASTM C580. Standard Test Method for Flexural Strength and Modulus of Elasticity of Chemical-Resistant Mortars, Grouts, Monolithic Surfacings, and Polymer Concretes; 2012.

[43] D'Antino T. Bond behavior in fiber reinforced polymer composites and fiber reinforced cementitious matrix composites. $\mathrm{PhD}$ Thesis, Università di Padova.

[44] Carloni C, D'Antino T, Sneed LH, Pellegrino C. Role of the Matrix Layers in the StressTransfer Mechanism of FRCM Composites Bonded to a Concrete Substrate. J Eng Mech 2015;141(6).

[45] Pham K, Marigo JJ, Maurini C. The issues of the uniqueness and the stability of the homogeneous response in uniaxial tests with gradient damage models, J. Mech. Phys. Solids 2011;59:1163-1190. 
[46] Farrell PE, Maurini C. Linear and nonlinear solvers for variational phase-field models of brittle fracture, Int. J. Numer. Meth. Eng 2015;00:1-21.

[47] Bažant, Z., Planas, S.T.: Fracture and Size-Effect in Concrete and other Quasi-Brittle Materials. CRC Press, New York, 1998. 